\title{
Elucidating the Role of the Aluminous Source on Limestone Reactivity in Cementitious Materials
}

\author{
Guillermo Puerta-Falla, ${ }^{\ddagger}$ Magdalena Balonis, ${ }^{\S}{ }^{\Uparrow}$ Gwenn Le Saout, ${ }^{\|}$Gabriel Falzone, ${ }^{\ddagger}$ Carolyn Zhang, ${ }^{\ddagger}$ \\ Narayanan Neithalath, ${ }^{\dagger \dagger}$ and Gaurav Sant ${ }^{\mathrm{t}, \mathrm{t}, \dagger}$ \\ ${ }^{*}$ Laboratory for the Chemistry of Construction Materials $\left(\mathrm{LC}^{2}\right)$, Department of Civil and Environmental Engineering, \\ University of California, Los Angeles, California \\ ${ }^{\S}$ Department of Materials Science and Engineering, University of California, Los Angeles, California \\ "Institute for Technology Advancement, University of California, Los Angeles, California \\ "Centre des Matériaux de Grande Diffusion (CMGD), École des Mines d’Alès, Alès, Cedex, France \\ ${ }^{\dagger}$ School of Sustainable Engineering and the Built Environment, Arizona State University, Tempe, Arizona \\ \California Nanosystems Institute (CNSI), University of California, Los Angeles, California
}

\begin{abstract}
When limestone $\left(\mathrm{CaCO}_{3}\right)$ is present in ordinary portland cement (OPC), carbonate-AFm phases (i.e., hemi- and/or mono-carboaluminate) are stabilized at the expense of the sulfate-AFm, which is more commonly found in cement systems. In OPC, the quantity of AFm hydrates formed is often limited by the availability of aluminum. Therefore, as a means of enhancing AFm phase formation, this study elucidates the role of aluminous sources including: calcium aluminate cements, metakaolin, and a hydratable alumina to determine if their addition would enhance limestone reactions and carbonateAFm formation in cement systems. The results of a detailed study including: X-ray diffraction, strength measurements, thermogravimetric analysis, and thermodynamic calculations are used to quantify solid phase constitutions, and the extent of limestone reacted. The results suggest that, the amount of limestone reacted and the specific carbonate-AFm formed is sensitive to both, the nature of the aluminous source and limestone content. Pozzolanic reactions which occur when metakaolin is used as an aluminous source are noted to be especially beneficial in offsetting the effects of OPC replacement. It is noted that although the different aluminous materials react with different quantities of $\mathrm{CaCO}_{3}$ during hydration, enhanced carbonate-AFm formation alone is insufficient to ensure strength equivalence, when OPC is replaced by limestone.
\end{abstract}

\section{Introduction}

$\mathrm{CO}_{2}$ pressures facing the construction industry are providing increasing impetus to reduce the use of ordinary portland cement (OPC) as the primary binder in concrete. ${ }^{1}$ Toward reducing OPC use, emphasis has been placed on replacing OPC with supplementary cementitious materials (SCMs) in the form of: fly ash, blast furnace slags, silica fume, etc. ${ }^{2,3}$ While capable of providing suitable properties, quantities of common SCMs available to replace OPC are often, especially at the local level, inadequate to satiate the desired OPC replacement demand. ${ }^{4,5}$ Due to concerns of the limited and the localized availability of SCMs, there is interest in using

G. Scherer-contributing editor limestone $\left(\mathrm{CaCO}_{3}\right)$, an abundant mineral, to reduce clinker factors of OPC, and therefore OPC use in concrete. However, the replacement of OPC by limestone induces a variety of effects including:

1. Dilution and strength reduction, ${ }^{6-8}$

2. Accelerated hydration at early ages that results from the so-called filler effects, ${ }^{9}$ and,

3. Changes in particle packing, and hence the microstructure that result when the limestone used has a particle size different from the cement ${ }^{10}$

Of these effects, dilution, that is, the reduction in strength that accompanies OPC replacement is a considerable issue, as technologically this is the most significant limitation which has ensured that, in practice, OPC replacement by $\mathrm{CaCO}_{3}$ remains limited, and most often on the order of less than or equal to $15 \%$ on a mass basis (ASTM C595). ${ }^{11}$

OPC is comprised of four main phases: tricalcium silicate $\left(\mathrm{C}_{3} \mathrm{~S}\right)$, dicalcium silicate $\left(\mathrm{C}_{2} \mathrm{~S}\right)$, tricalcium aluminate $\left(\mathrm{C}_{3} \mathrm{~A}\right)$, and the ferrite $\left(\mathrm{C}_{4} \mathrm{AF}\right)$ phases, wherein the kinetics of hydration of each phase differs from the others. ${ }^{a}, 12$ Hydration of the $\mathrm{C}_{3} \mathrm{~A}$ in the presence of gypsum $\left(\mathrm{CS}_{\bar{S}} \mathrm{H}_{2}\right)$, forms ettringite $\left(\mathrm{C}_{6} \mathrm{~A} \overline{\mathrm{S}}_{3} \mathrm{H}_{32}, \mathrm{AFt}\right)$ at early ages and monosulfoaluminate $\left(\mathrm{C}_{4} \mathrm{~A} \overline{\mathrm{S}} \mathrm{H}_{12}\right.$, sulfate-AFm, Ms), at later ages when the sulfate source is exhausted. However, when carbonate ions may be present, for example, when provisioned by the dissolution of limestone, $\mathrm{C}_{3} \mathrm{~A}$ reacts with carbonate species to form the $\mathrm{CO}_{3}$-AFm (i.e., carbonate-AFm) phases. $^{13-16}$ Typically, monocarboaluminate $\left(\mathrm{C}_{4} \mathrm{~A} \overline{\mathrm{C}} \mathrm{H}_{11}, \mathrm{Mc}\right)$ forms when there is an abundance of calcium carbonate present, and hemicarboaluminate $\left(\mathrm{C}_{4} \mathrm{~A}_{0.5} \mathrm{H}_{12}, \mathrm{Hc}\right)$ forms under carbonate-deficient conditions. ${ }^{13,14}$ The presence of the $\mathrm{CaCO}_{3}$ has also been shown to limit the transformation of the ettringite into Ms. ${ }^{13-16} \mathrm{C}_{4} \mathrm{AF}$ forms similar hydration products as $\mathrm{C}_{3} \mathrm{~A}$, but the kinetics of its reactions are slower. ${ }^{17}$ These reactions are detailed in Eqs. (1-5). While the mass balance of the AFt and $\mathrm{AFm}$ phases formed is dictated by the $\mathrm{SO}_{3} / \mathrm{Al}_{2} \mathrm{O}_{3}$ and $\mathrm{CO}_{2} / \mathrm{Al}_{2} \mathrm{O}_{3}$ ratio(s) of the binder, the stabilization of the $\mathrm{CO}_{3}$-AFm phases is a significant observation ${ }^{13-15}$ which indicates that when a favorable (i.e., aluminate rich) chemistry exists, carbonaceous reactions resulting in the formation of

a Standard cement chemistry notation is used. As per this (short-hand) notation: $\mathrm{C}=\mathrm{CaO}, \quad \mathrm{H}=\mathrm{H}_{2} \mathrm{O}, \quad \mathrm{A}=\mathrm{Al}_{2} \mathrm{O}_{3}, \quad \mathrm{~F}=\mathrm{Fe}_{2} \mathrm{O}_{3}, \quad \mathrm{~T}=\mathrm{TiO}_{2}, \quad C \overline{\mathrm{S}} \mathrm{H}_{2}=\mathrm{CaSO}_{4} \cdot 2 \mathrm{H}_{2} \mathrm{O}$, $\bar{S}=\mathrm{SO}_{3}$ and $\bar{C}=\mathrm{CO}_{2}$. 
$\mathrm{CO}_{3}$-AFm phases can be provoked and perhaps enhanced in cementitious systems.

$$
\begin{aligned}
& \mathrm{C}_{3} \mathrm{~A}+3 \mathrm{C} \overline{\mathrm{S}} \mathrm{H}_{2}+26 \mathrm{H} \rightarrow \mathrm{C}_{6} \mathrm{~A}_{3} \mathrm{H}_{32} \\
& 2 \mathrm{C}_{3} \mathrm{~A}+\mathrm{C}_{6} \mathrm{~A}_{3} \mathrm{H}_{32}+4 \mathrm{H} \rightarrow 3 \mathrm{C}_{4} \mathrm{~A} \overline{\mathrm{S}} \mathrm{H}_{12} \\
& \mathrm{C}_{3} \mathrm{~A}+\mathrm{C} \overline{\mathrm{C}}+11 \mathrm{H} \rightarrow \mathrm{C}_{4} \mathrm{~A} \overline{\mathrm{C}} \mathrm{H}_{11} \\
& \mathrm{C}_{3} \mathrm{~A}+0.5 \mathrm{C} \overline{\mathrm{C}}+0.5 \mathrm{CH}+11.5 \mathrm{H} \rightarrow \mathrm{C}_{4} \mathrm{AC}_{0.5} \mathrm{H}_{12} \\
& 3 \mathrm{C}_{4} \mathrm{~A} \overline{\mathrm{S}} \mathrm{H}_{12}+2 \mathrm{C} \overline{\mathrm{C}}+18 \mathrm{H} \rightarrow \mathrm{C}_{6} \mathrm{~A}_{3} \mathrm{H}_{32}+2 \mathrm{C}_{4} \mathrm{~A} \overline{\mathrm{C}} \mathrm{H}_{11}
\end{aligned}
$$

In typical OPCs, the aluminate (mainly $\mathrm{C}_{3} \mathrm{~A}$ ) phase content is regulated by governing standards (ASTM C595). ${ }^{11}$ This ensures that the extent of $\mathrm{CaCO}_{3}$ that can react in a typical OPC is quite small and in the range $2 \%-5 \%$ (by mass). ${ }^{13}$ As such, if it is desirable to increase $\mathrm{CaCO}_{3}$ reactivity (defined herein as the rate, and extent of reaction) and thus OPC replacement by limestone, it is also necessary to enhance the quantity of aluminous phases present. Such enhancements would provide sufficient $\mathrm{Al}(\mathrm{OH})_{4}{ }^{-}$(aluminate) species, which under conditions of portlandite saturation would react with $\mathrm{CaCO}_{3}$ to produce $\mathrm{CO}_{3}$-AFm phases. While a variety of aluminous substances exist, the characteristics of an optimal aluminous source remain unclear. To better understand these aspects, this work evaluates a variety of commercially available aluminous substances including: (1) a gray calcium aluminate cement (CAC1), (2) a white calcium aluminate cement (CAC2), (3) metakaolin (MET), and (4) an amorphous, finely divided hydratable alumina (HA). ${ }^{\mathrm{b}}$ Each aluminous source is studied separately, in both limestone deficient and excess systems (i.e., $\mathrm{CaCO}_{3}$ contents ranging between $3.5 \%$ and $32 \%$, by mass of binder). Deficiency corresponds to the presence of limestone intrinsic to the OPC, whereas excess corresponds to the replacement of OPC by limestone at a dosage of $30 \%$, by mass. The results are harmonized to comment on the suitability of an aluminous agent as being capable of provoking/enhancing limestone reactions. Based on critical assessments, metakaolin and hydratable alumina are identified to be the best aluminous agents.

\section{Materials and Methods}

\section{(1) Materials}

An ASTM C150 11 compliant Type I/II OPC was used. The limestone used is a commercially available $\left(>95 \% \mathrm{CaCO}_{3}\right)$ product produced by OMYA A.G. ${ }^{\mathrm{c}}$ The oxide compositions (disregarding minor oxides and renormalized to $100 \%$, mass basis) of the OPC and the aluminous agents are presented in Table I, along with their mineralogical compositions in Table II. It is important to note the " $\mathrm{Al}_{2} \mathrm{O}_{3}$ " present in CAC2 corresponds to corundum, which presents marginal (if any) reactivity in aqueous environments. ${ }^{18}$ This is a consequence of the CAC2's intended use for refractory applications. HA and MET are amorphous compounds, though some traces of $\mathrm{TiO}_{2}$ (anatase) are noted in MET. Table II additionally presents values of median particle size $\left(d_{50}, \mu \mathrm{m}\right)$ and specific surface area of the solid reactants used in this study.

${ }^{\mathrm{b}}$ The hydratable alumina (HA) is a finely divided, amorphous substance produced via a calcination process. This substance is highly hydrophilic showing substantial and strong water adsorption, and due to the presence of $\mathrm{Na}_{2} \mathrm{O}$ impurity left-over from the synthesis process, and its amorphous nature, it shows some solubility in water.

${ }^{\mathrm{c}}$ Certain commercial materials and equipment are identified to adequately specify experimental procedures. In no case does such identification imply recommendation or endorsement by University of California, Los Angeles, École des Mines d'Alès, or Arizona State University, nor does it imply that the items identified are necessarily the best available for the purpose.
Table I. The Simple Oxide Compositions of the Solid Materials Utilized in This Study as Determined Using X-Ray Fluorescence

\begin{tabular}{lrrrrr}
\hline Oxide $(\%)$ & Type I/II OPC & \multicolumn{1}{c}{ CAC1 } & CAC2 & \multicolumn{1}{c}{ HA } & MET \\
\hline $\mathrm{SiO}_{2}$ & 20.54 & 4.87 & 0.00 & 0.34 & 51.36 \\
$\mathrm{Al}_{2} \mathrm{O}_{3}$ & 4.97 & 52.12 & 80.27 & 98.99 & 47.60 \\
$\mathrm{Fe}_{2} \mathrm{O}_{3}$ & 3.10 & 2.28 & 0.10 & 0.00 & 0.39 \\
$\mathrm{CaO}$ & 65.75 & 39.75 & 18.76 & 0.11 & 0.02 \\
$\mathrm{MgO}$ & 2.43 & 0.60 & 0.37 & 0.00 & 0.09 \\
$\mathrm{SO}_{3}$ & 2.75 & 0.00 & 0.00 & 0.00 & 0.08 \\
$\mathrm{Na}_{2} \mathrm{O}$ & 0.18 & 0.07 & 0.50 & 0.56 & 0.28 \\
$\mathrm{~K}_{2} \mathrm{O}$ & 0.29 & 0.32 & 0.00 & 0.00 & 0.18 \\
Total & 100.00 & 100.00 & 100.00 & 100.00 & 100.00 \\
\hline
\end{tabular}

A series of cementitious paste mixtures were prepared using de-ionized (DI) water at a fixed water-to-solids ratio $(w / s=0.45$, mass basis) using a planetary mixer as described in ASTM C305. ${ }^{11}$ The series of mixtures produced comprised: (A) a plain OPC paste, (B) a cementitious paste in which $30 \%$ of the OPC (mass basis) is replaced by fine limestone, (C) cementitious pastes in which $5 \%-15 \%$ of the OPC is replaced in 5\% increments (by mass) by a given aluminous source and (D) cementitious pastes in which $5 \%$ $15 \%$ of the OPC is replaced in $5 \%$ increments by a given aluminous source and an additional $30 \%$ of the OPC is then replaced by fine limestone. All OPC replacements are carried out on a mass basis. As such, the cement factor $(\mathrm{CF}$, i.e., the quantity of clinker + gypsum in a given mixture, as a fraction $^{\mathrm{d}}$ ) ranges between: (A) $\mathrm{CF}=0.96$ (i.e., the $\mathrm{CaCO}_{3}$ content in the OPC is $3.7 \%$, by mass), (B) $\mathrm{CF}=0.67$, (C) $0.82 \leq \mathrm{CF} \leq 0.91$ and (D) $0.53 \leq \mathrm{CF} \leq 0.67$ for the range of mixtures considered.

To discount early age kinetic effects, our evaluations are restricted to determinations at 28 and $90 \mathrm{~d}$, at which time the systems are expected to have hydrated substantially. This selection is made to permit characterizations when the systems presents near equilibrium constitutions. It should be noted that the mixtures evaluated present wide-ranges of sulfate-to-alumina $\left(\mathrm{SO}_{3} / \mathrm{Al}_{2} \mathrm{O}_{3}\right)$ and carbonate (equivalent $\mathrm{CO}_{2}$ )to-alumina $\left(\mathrm{CO}_{2} / \mathrm{Al}_{2} \mathrm{O}_{3}\right)$ ratios, by mass, as a function of the aluminous source, and the extent of OPC replacement (see Fig. 1). The changes in the binder chemistry are provoked to alter the AFt, and AFm phase balances, and to favor the formation of $\mathrm{CO}_{3}$-AFm phases. These aspects will be discussed in detail later. It should be noted that cementitious binders are produced to a sulfate optimum which regulates setting time, strength gain, etc. The cementitious binders formulated herein were not optimized for sulfates under the assumption that the OPC used is already optimized, in terms of its sulfate content. Also, in contrast to practical circumstances, the (non-OPC) materials used were of a high-purity, a reflection of the laboratory-scope of the work.

\section{(2) Particle Size Analysis Using Light Scattering}

The particle size distributions [PSDs, Fig. 1(c)] of the solids were measured using a Beckman Coulter Static Light Scattering Analyzer (LS13-320) using isopropanol (IPA) and ultrasonication for dispersing the powders to primary particles. The uncertainty in the light scattering analysis was determined to be $\approx 6 \%$ based on analysis of six replicate samples assuming the density of the OPC, limestone, MET, CAC1, CAC2, and HA to be $3150,2700,2200,3150,3040$, and $3200 \mathrm{~kg} / \mathrm{m}^{3}$, respectively.

The PSD of the HA could not be sampled due to significant particle agglomeration, flocculation and clumping. Based on

\footnotetext{
${ }^{\mathrm{d}}$ The cement factor (CF, unitless) as defined herein refers to the quantity of clinker + gypsum in a mixture. As such, the CF disregards all limestone, intrinsic to, and added to the mixture, that is, by OPC replacement.
} 
Table II. Density, Median Particle Diameter $\left(d_{50}\right)$, Specific Surface Area (SSA) and the Mineralogical Components of Solid Reactants Used in This Study

\begin{tabular}{|c|c|c|c|c|c|c|}
\hline Property & Type I/II OPC & $\mathrm{CACl}$ & $\mathrm{CAC} 2$ & MET & HA & Limestone \\
\hline$d_{50}(\mu \mathrm{m})$ & 8.5 & 8.15 & 2.66 & 5.11 & 7.09 & 3.06 \\
\hline $\mathrm{C}_{3} \mathrm{~S}(\%)$ & 57.8 & - & - & - & - & - \\
\hline $\mathrm{C}_{2} \mathrm{~S}(\%)$ & 18.2 & - & - & - & - & - \\
\hline $\mathrm{C}_{3} \mathrm{~A}(\%)$ & 5.5 & - & - & - & - & - \\
\hline $\mathrm{MgO}(\%)$ & 1.3 & - & - & - & - & - \\
\hline $\mathrm{CaSO}_{4} \cdot 2 \mathrm{H}_{2} \mathrm{O}(\%)$ & 0.8 & - & - & - & - & - \\
\hline $\mathrm{CaSO}_{4} \cdot 0.5 \mathrm{H}_{2} \mathrm{O}(\%)$ & 1 & - & - & - & - & - \\
\hline $\mathrm{CaSO}_{4}(\%)$ & 1.2 & - & - & - & - & - \\
\hline CA $(\%)$ & - & 73.3 & 38.1 & - & - & - \\
\hline $\mathrm{C}_{2} \mathrm{AS}(\%)$ & - & 18.1 & - & - & - & - \\
\hline $\mathrm{C}_{12} \mathrm{~A}_{7}(\%)$ & - & - & 5.8 & - & - & - \\
\hline $\mathrm{CaO}(\%)$ & 0.5 & 0.8 & - & - & - & - \\
\hline $\mathrm{Al}_{2} \mathrm{O}_{3}(\%)$ & - & - & 48.6 & - & - & - \\
\hline $\mathrm{Fe}_{2} \mathrm{O}_{3}(\%)$ & - & 0.8 & - & - & - & - \\
\hline $\mathrm{CaCO}_{3}(\%)$ & 4.2 & - & - & - & - & 98.08 \\
\hline
\end{tabular}

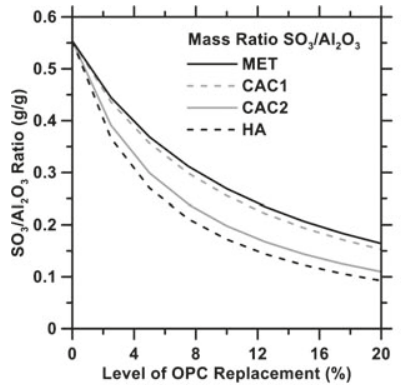

(a)

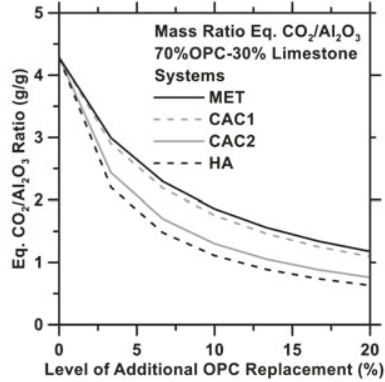

(b)

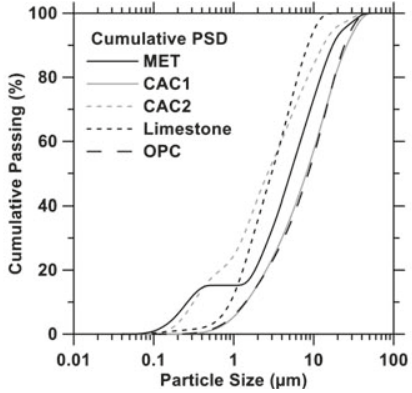

(c)

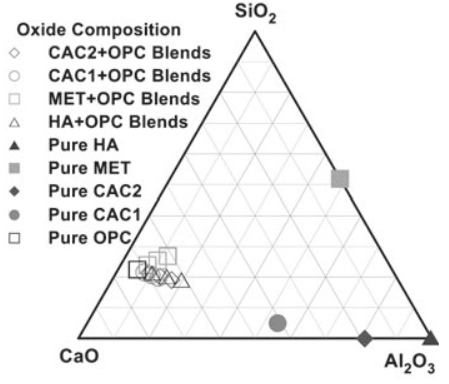

(d)

Fig. 1. (a) Sulfate-to-alumina $\left(\mathrm{SO}_{3} / \mathrm{Al}_{2} \mathrm{O}_{3}\right)$ mass ratio as a function of increasing OPC replacement by a given alumina source, (b) Carbon dioxide equivalent-to-alumina $\left(\mathrm{CO}_{2} / \mathrm{Al}_{2} \mathrm{O}_{3}\right)$ mass ratio for the mixtures containing $30 \%$ of limestone (dosed by OPC replacement) as a function of increasing OPC replacement by a given alumina source, (c) The cumulative particle size distributions of the powders, and, (d) The compositions of the binders, minus limestone, plotted on a ternary composition diagram (with $\mathrm{CaO}-\mathrm{SiO}_{2}-\mathrm{Al}_{2} \mathrm{O}_{3}$ at the vertices).

data provided by the manufacturer, the $\mathrm{HA}$ presents a $\mathrm{N}_{2-}$ BET sampled surface area in excess of $10000 \mathrm{~m}^{2} / \mathrm{kg}$. Based on the measured PSD, the MET, CAC1, CAC2, OPC, and limestone present surface areas of: $1741,506,1844,510$, and $1353 \mathrm{~m}^{2} / \mathrm{kg}$, respectively, assuming that their particles are spherical. This assumption can result in an underestimation of the surface area by a factor of $1.6-1.8 .{ }^{19}$

\section{(3) Compressive Strength Measurements}

Compressive strength measurements were carried out at 28 and $90 \mathrm{~d}$ using cubic specimens $(50 \mathrm{~mm} \times 50 \mathrm{~mm} \times 50 \mathrm{~mm})$ cured at $25^{\circ} \mathrm{C} \pm 1{ }^{\circ} \mathrm{C}$ in lime water as described in ASTM C109. ${ }^{11}$ The strength reported is the average of three specimens cast from the same batch. The coefficient of variation in the measured strength data was in general less than $8 \%$ across all samples.

\section{(4) Thermal Analysis (TGA/DTG/DTA)}

A Perkin Elmer (Waltham, MA) STA 6000 simultaneous thermal analyzer with a Pyris data acquisition interface was used to determine solid phase quantities in cementitious mixtures. The temperature and mass sensitivity of the analyzer used were $0.25^{\circ} \mathrm{C}$ and $0.1 \mu \mathrm{g}$, respectively. To arrest hydration, solvent exchange was performed using isopropanol wherein at a desired age, the hydrated pastes were crushed to a size less than $5 \mathrm{~mm}$ and submerged in isopropanol for $14 \mathrm{~d}$, with isopropanol being replaced at $7 \mathrm{~d} .{ }^{20}$ Following solvent exchange, samples were placed under vacuum, to remove the solvent, and in a desiccator for another $7 \mathrm{~d}$. After this, all the samples were finely powdered.

The powder samples were heated under UHP-N 2 purge at a flow rate of $20 \mathrm{~mL} / \mathrm{min}$ and a heating rate of $10^{\circ} \mathrm{C} /$ min in neat aluminum oxide crucibles over a temperature range from $35^{\circ} \mathrm{C}$ to $975^{\circ} \mathrm{C}$. The weight loss (TG) and differential weight loss (DTG) patterns acquired were used to ascertain the quantities of $\mathrm{Ca}(\mathrm{OH})_{2}, \mathrm{CaCO}_{3}$, evaporable, and nonevaporable water present in the system. It should be noted that amount of phases (portlandite and $\mathrm{CaCO}_{3}$ ) derived from TGA studies are presented in two forms: as a percentage amount of phase present in the dry paste $(\%$ dry mass) and as percentage amount of phase present in the dry paste normalized by the OPC content ( $\%$ dry mass $/ \mathrm{CF}$ ) to account for reductions in the OPC content (i.e., dilution). 
(5) Quantitative X-ray Diffraction Analysis Using Rietveld Refinement (QXRD)

Quantitative X-ray diffraction analyses were carried out on powdered cementitious mixtures at desired ages using a Bruker D8-Advance diffractometer in a $\theta-\theta$ configuration using $\mathrm{Cu} K_{\alpha}$ $(\lambda=1.54 \AA)$ radiation. Samples were scanned between $5^{\circ}$ and $70^{\circ}(2 \theta)$ in continuous mode with an integrated step scan of $0.017^{\circ}(2 \theta)$ using a VANTEC-1 detector. The time required for acquisition of X-ray diffraction patterns was around $12 \mathrm{~min}$. A fixed divergence slit of $0.50^{\circ}$ was used during data acquisition. Care was taken to minimize preferred orientation errors by texturing the sample surface. A rotating stage was used to suitably sample the powder during acquisition.

$\mathrm{X}$-ray structure information for the relevant anhydrous and the hydrated crystalline phases were sourced from standard databases or from the literature. ${ }^{21}$ Anhydrous materials were analyzed using a protocol described in Ref. [22] For the hydrated pastes, an external standard (i.e., G-factor approach) was used to quantify the X-ray amorphous substances. ${ }^{23-25}$ The mass attenuation coefficients of the samples were determined by X-ray fluorescence (XRF) analysis taking into account the amount of bound water that was determined by TGA. Results of Rietveld analyses provide the sum of the phases normalized to 100 mass $\%$. Due to chemical reactions, water is bound in the hydrates, so the total amount of solids increases. To correct for this effect, the amount of bound water was determined (by TGA analysis); so the results refer to the mass of anhydrous materials. The results of Rietveld quantifications in such complex mixtures should be considered carefully, and are thus semiquantitative rather than absolute.

\section{(6) Thermodynamic Calculations: Prediction of Hydrated Phase Assemblages}

Thermodynamic calculations were carried out using a geochemical speciation code, GEMS-PSI: Gibbs Energy Minimization Software, version 2.3.1. ${ }^{26}$ GEMS uses the initial mixture proportions represented in the form of simple oxides for the solid precursors and the water content, as inputs and applies a convex programming approach in conjunction with datasets of the thermodynamic properties of phases (i.e., solids, liquid, and air) to compute equilibrium phase balances and ionspeciation in a multicomponent system. Thermodynamic data of solid and aqueous species were sourced from the GEMS-PSI database, and then amended with additional information relevant to cementitious systems ${ }^{27-32}$; Table III. Equilibrium phase balances and solution phase compositions for the systems considered in this study were computed under standard conditions $\left(1 \mathrm{bar}, 25^{\circ} \mathrm{C}\right)$. The simple oxide compositions of the solids (i.e., OPC, CAC, limestone, etc.), were determined by $\mathrm{XRF}$ analyses (Table I). The gas phase at equilibrium with the solids and the liquid phase were set to be $\mathrm{CO}_{2}$-free air.

$\mathrm{C}-\mathrm{S}-\mathrm{H}$ phases are described within GEMS using the solidsolution model proposed by Kulik and Kersten. ${ }^{33}$ In this model jennite $\left[(\mathrm{CaO})_{1.67}\left(\mathrm{SiO}_{2}\right) \cdot\left(\mathrm{H}_{2} \mathrm{O}\right)_{2.1}\right]$, tobermorite $\left[(\mathrm{CaO})_{0.83}\left(\mathrm{SiO}_{2}\right) \cdot\left(\mathrm{H}_{2} \mathrm{O}\right)_{1.3}\right]$, and amorphous silica $\left(\mathrm{SiO}_{2}\right)$ are used as end-members of two different solid solution series where one solid solution (tobermorite-jennite) describes the range $0.83 \leq(\mathrm{Ca} / \mathrm{Si}) \mathrm{C}-\mathrm{S}-\mathrm{H} \leq 1.67$, whereas a second solid solution (amorphous silica-tobermorite) is used to describe the range $0 \leq(\mathrm{Ca} / \mathrm{Si}) \mathrm{C}-\mathrm{S}-\mathrm{H} \leq 0.83$. No account is made for the influences of Al-substitution in the $\mathrm{C}-\mathrm{S}-\mathrm{H}$, because the thermodynamic phase relations for such modifications to the $\mathrm{C}-\mathrm{S}-\mathrm{H}$ structure are not fully clear. ${ }^{34,35}$ Thermodynamic data of relevant AFt, AFm, and Fe-bearing phases were taken from the literature and used as is. ${ }^{16,36,37}$

XRD datasets revealed the existence of a phase lying along the grossular-hydrogarnet phase line ${ }^{14,36}$ (see discussion below). Comparison to patterns of neat hydrogarnet revealed a slight right-shift, presumably caused due to Si-substitution. $^{38-40}$ Jappy and Glasser ${ }^{40}$ studied a range of silica substituted hydrogrossular-like phases (Hy) with end-members,
Table III. The Gibbs Free Energies of Formation and Molar Volumes for Relevant Hydrated Phases at $25^{\circ} \mathrm{C}$ and $p=1 \operatorname{bar}^{27}$

\begin{tabular}{|c|c|c|}
\hline Phase & $\Delta_{\mathrm{f}} G^{0}(\mathrm{~kJ} / \mathrm{mol})$ & $V\left(\mathrm{~cm}^{3} / \mathrm{mol}\right)$ \\
\hline $\mathrm{C}_{3} \mathrm{AH}_{6}$ & -5010.1 & 150 \\
\hline $\mathrm{C}_{3} \mathrm{AS}_{0.8} \mathrm{H}_{4.4}$ & -5368 & 143 \\
\hline $\mathrm{C}_{3} \mathrm{AS}_{0.1} \mathrm{H}_{5.8}$ & -5054.7 & 149 \\
\hline $\mathrm{C}_{3} \mathrm{AS}_{0.02} \mathrm{H}_{5.96}$ & -5018.8 & 143 \\
\hline $\mathrm{C}_{3} \mathrm{AS}_{0.015} \mathrm{H}_{5.96}$ & -5016.8 & 143 \\
\hline $\mathrm{C}_{4} \mathrm{AH}_{13}$ (hydroxy-AFm) & -7326.6 & 274 \\
\hline $\mathrm{C}_{4} \mathrm{AsH}_{12}$ (monosulfoaluminate) & -7778.5 & 309 \\
\hline $\mathrm{C}_{4} \mathrm{AcH}_{11}$ (monocarboaluminate) & -7337.5 & 261 \\
\hline $\mathrm{C}_{4} \mathrm{Ac}_{0.5} \mathrm{H}_{12}$ (hemicarboaluminate) & -7336 & 285 \\
\hline $\mathrm{C}_{2} \mathrm{ASH}_{8}$ (strätlingite) & -5705.1 & 216 \\
\hline $\mathrm{M}_{4} \mathrm{AH}_{10}(\mathrm{OH}-$ hydrotalcite $)$ & -6394.56 & 220 \\
\hline $\mathrm{M}_{4} \mathrm{AcH}_{9}\left(\mathrm{CO}_{3}\right.$-hydrotalcie $)$ & -6580.15 & 220 \\
\hline Brucite, $\mathrm{Mg}(\mathrm{OH})_{2}$ & -832.23 & 25 \\
\hline $\mathrm{C}_{6} \mathrm{AsH}_{32}$ (sulfate-ettringite) & -15205.9 & 707 \\
\hline $\mathrm{C}_{6} \mathrm{AcH}_{32}$ (carbonate-ettringite) & -14565.6 & 650 \\
\hline Water $\left(\mathrm{H}_{2} \mathrm{O}\right)$ & -237.2 & 18 \\
\hline $\mathrm{SiO}_{2}$ (amorphous) & -848.9 & 29 \\
\hline C-S-H, tobermorite-type: $\mathrm{C}_{0.83} \mathrm{SH}_{1.3}$ & -1744.4 & 59 \\
\hline $\mathrm{C}-\mathrm{S}-\mathrm{H}$, jennite-type: $\mathrm{C}_{1.67} \mathrm{SH}_{2.1}$ & -2480.8 & 78 \\
\hline $\mathrm{Fe}(\mathrm{OH})_{3}$ (microcrystalline) & -711.6 & 34 \\
\hline $\mathrm{Al}(\mathrm{OH})_{3}$ (amorphous) & -1143.21 & 32 \\
\hline $\mathrm{Al}(\mathrm{OH})_{3}$ (gibbsite) & -1151 & 32 \\
\hline Portlandite, $\mathrm{Ca}(\mathrm{OH})_{2}, \mathrm{CH}$ & -897 & 33 \\
\hline Calcite, $\mathrm{CaCO}_{3}, \mathrm{Cc}$ & -1129.2 & 37 \\
\hline Gypsum, $\mathrm{CaSO}_{4} \cdot 2 \mathrm{H}_{2} \mathrm{O}$ & -1797.8 & 75 \\
\hline
\end{tabular}

$\mathrm{C}_{3} \mathrm{AH}_{6}-\mathrm{C}_{3} \mathrm{AS}_{3}$. They reported that the unit cell size decreases as the silicon ( $\mathrm{Si}$ ) content increases. However, it is challenging to precisely link the XRD peak position to the exact Si-content due to the presence of a range of solid solutions between compositions of $\mathrm{C}_{3} \mathrm{AH}_{6}-\mathrm{C}_{3} \mathrm{AS}_{0.42} \mathrm{H}_{5.16}$ and $\mathrm{C}_{3} \mathrm{AS}_{0.76} \mathrm{H}_{4.48}$ $\mathrm{C}_{3} \mathrm{AS}_{3}$. Preliminary simulations which considered formation of $\mathrm{C}_{3} \mathrm{AS}_{0.8} \mathrm{H}_{4.4}$ (i.e., a hydrogrossular phase provided in the standard thermodynamic database for cement hydrates ${ }^{14}$ ) indicated that the formation of hemicarboaluminate $(\mathrm{Hc})$ would be suppressed in mixtures considered in this study. This finding was in contradiction with our experimental (XRD) data (see below).

To resolve this inconsistency parametric variations of the silicon content in the hydrogrossular phase were considered (i.e., by interpolating solubility constants, and the density data provided in ${ }^{40}$ along the end-members: $\mathrm{C}_{3} \mathrm{AH}_{6}-\mathrm{C}_{3} \mathrm{AS}_{3}$ ) until the existence of hemicarboaluminate $(\mathrm{Hc})$ was satisfied in relevant systems. The formation of a hydrogrossular-type phase with a (presumed) composition of $\mathrm{C}_{3} \mathrm{AS}_{0.02} \mathrm{H}_{5.96}$ was predicted for systems containing MET and $\mathrm{CAC} 2$. In the case of $\mathrm{HA}$ and $\mathrm{CACl}$ containing mixtures, the silica content in the hydrogrossular phase were found to range between 0.015 and 0.100 (molar units), respectively. While this is admittedly a trial-and-error means of designating phase equilibria, this choice was made to ensure consistency between the simulations, and the experimental phase analysis. It should be clarified, the thermodynamic properties (Gibbs free energy of formation) of the hydrogrossular phases as calculated herein, are sensitive to composition. Therefore, the compositions identified, are approximate at best. ${ }^{40}$

When magnesium is present, hydrotalcite-type phases, which can demonstrate multiplicity in ion uptake, are stabilized. ${ }^{41,42}$ While $\mathrm{OH}$-hydrotalcite is often observed, ${ }^{43-45}$ for example, in slag bearing cementitious system, in the presence of excess carbonate, it is possible that the $\mathrm{CO}_{3}$-hydrotalcite phase (i.e., in addition to the $\mathrm{CO}_{3}$ - $\mathrm{AFm}$ variants) would form. Preliminary simulations carried out under conditions of excess $\mathrm{Ca}(\mathrm{OH})_{2}$ indicate that, $\mathrm{OH}$-hydrotalcite forms in preference 
to $\mathrm{CO}_{3}$-hydrotalcite, independent of the presence, or absence, of calcite. Therefore, within the scope of thermochemical data presently available, $\mathrm{OH}$-hydrotalcite $\left(\mathrm{M}_{4} \mathrm{AH}_{10}\right)$ is the only phase that is assumed to form but it is possible, and indeed likely, that in the real cement systems hydrotalcite-type phases substituted with other ions may also precipitate.

All calculations were carried out applying a progressive equilibrium approach which enabled to account for fractional reactivity (i.e., incomplete reaction) of each of the components: (1) OPC, (2) aluminous source, and (3) limestone. The amount of OPC reacted was set to be $86 \% \pm 5 \%$ and $91 \% \pm 5 \%$ after 28 and $90 \mathrm{~d}$ of hydration, respectively, as determined using QXRD analyses, across all mixtures TGA analysis of the anhydrous OPC showed calcite contents of $\approx 3.7 \%$, a value in compliance with the ASTM C150 specification. Once the degree of OPC reaction was fixed, the aluminous materials were let to incrementally "react" with the OPC oxides and the $\mathrm{CaCO}_{3}$ in $10 \%$ increments. These types of simulations retain the unhydrated fraction of OPC, whereas the quantity of the aluminous agent is systematically reduced as it is allowed to take part in hydration.

The GEMS simulations were matched to our experimental data by setting a "match point" to the portlandite content, as assessed by TGA, for systems containing amorphous aluminous sources (MET and HA). This match point serves as a means to estimate the degree of reaction of these aluminous materials as these systems are not amenable to QXRDbased quantifications. In the case of crystalline aluminous materials (i.e., the CAC's) the degree of aluminous material reacted was established by QXRD, and the match point established directly by Rietveld analysis of residual anhydrous (CAC) phase contents. It should be noted that while quantitative XRD with Rietveld refinement provides accurate values of the residual (or initial) quantities of the crystalline phases, quantifications of less ordered phases such as, C-S$\mathrm{H}, \mathrm{Hc}$, and $\mathrm{Mc}$ are less precise. ${ }^{46,47}$ This is not a limitation of QXRD techniques generally, but rather a result of the nature of measurements, and refinement procedures implemented herein. Furthermore, though the methodology used herein to establish the match points, varies for the crystalline and amorphous aluminous sources, both provide a means to assess equilibrium phase assemblages for the systems studied.

\section{Experimental Results and Discussion}

Figure 2 shows the compressive strength of the mixtures evaluated in this study after $90 \mathrm{~d}$ of hydration as a function of their OPC content $(\mathrm{CF})$. It is noted that the replacement of OPC by a given aluminous source and/or limestone, results in strength reduction. The reductions trace a decrease in the OPC content (i.e., dilution). It is noted that within the resolution of the measured data, there are two clusters, partitioned below, and above the "dilution line." Data lying above the line (e.g., MET additions, and higher levels of HA additions) show beneficial, synergistic effects of changes in the binder chemistry, whereas data lying below the line (e.g., $\mathrm{CAC}$ and quartz, where the latter is used as an inert reference) illustrate compromised binder compositions. The trends show that mechanical properties, in relation to the aluminous source scale as: MET $>\mathrm{HA}>\mathrm{CAC} 1>\mathrm{CAC} 2$ in a descending order. These trends cast a basis of considering the influence of a given aluminous agent on limestone reactions and associated phase balances in cementing mixtures.

\section{(1) Influence of Calcium Aluminate Cement (CAC) Additions}

When CAC's are used as an aluminous source, with or without excess limestone (i.e., for $0.53 \leq \mathrm{CF} \leq 0.96$ ), the compressive strength decreases monotonically. In fact, in the presence of the CAC's, the measured strengths are similar to

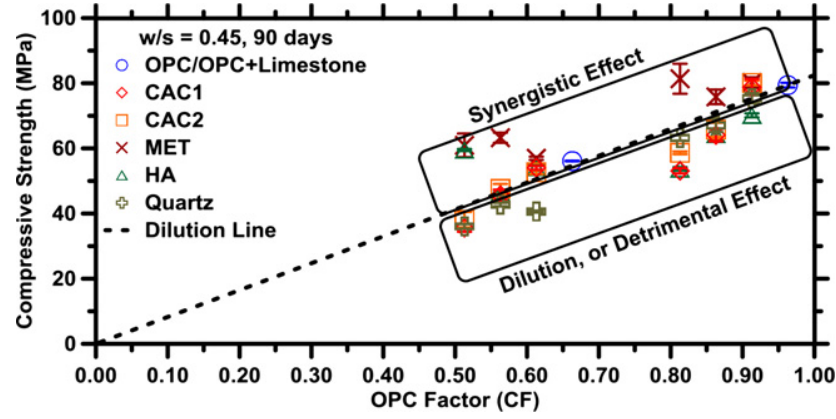

Fig. 2. The compressive strength as function of the CF at $90 \mathrm{~d}$, for all the systems studied herein. The dilution line traces the extent of compressive strength reduction that would occur as the OPC content (in terms of mass fraction) was systematically reduced. For the plain OPC formulation, $\mathrm{CF}=0.963$, given the presence of limestone therein. The error bars shown, indicate the uncertainty in the strength measurements.

those measured in the presence of quartz; an inert material. This suggests that in spite of their otherwise reactive nature (e.g., when used on their own), CAC additions, do little in terms of improving the mechanical response of OPC-dominated binders. To better understand these trends, Fig. 3 shows portlandite contents of blended (OPC + CAC) mixtures, determined by TGA at $90 \mathrm{~d}$ normalized by the cement content, to account for OPC replacement. At low levels of OPC replacement, the normalized portlandite content is similar to the reference OPC mixture. However, at higher levels of OPC replacement, a reduction is observed. This suggests either: (a) consumption of portlandite and/or (b) a possible reduction in the extent of OPC reaction.

$\mathrm{Gu}$ et al. ${ }^{48,49}$ studied blended binder systems containing OPC and CAC, and concluded that OPC hydration is suppressed only at early ages in sulfate-deficient conditions, that is, when aluminum is in excess. Since the title study only evaluates mature systems, such hydration suppression is not expected, a point which is validated by QXRD analysis. Portlandite consumption, on the other hand, seems to play an important role in hemicarboaluminate $(\mathrm{Hc})$ formation. $\mathrm{Kuze}^{50}$ showed that in the presence of a carbonate source, $\mathrm{C}_{3} \mathrm{~A}$ reacts with portlandite $(\mathrm{CH})$ to form $\mathrm{AFt}$ and $\mathrm{Hc}$ [Eq. (6)]. Matschei et al. ${ }^{14}$ additionally noted that coexistence of monosulfoaluminate (Ms) and monocarboaluminate (Mc) in the presence of $\mathrm{CH}$ is not possible as the system would stabilize AFt and $\mathrm{Hc}$ as shown in Eq. (7). This suggests that in the process of forming Hc, portlandite is consumed. This explanation is consistent with our XRD observations, as presented later in this study (i.e., which confirm Hc formation in the OPC-CAC blends).

$$
\begin{aligned}
& \quad 3 \mathrm{C}_{3} \mathrm{~A}+3 \mathrm{C} \overline{\mathrm{S}} \mathrm{H}_{2}+\mathrm{CH}+\mathrm{C} \overline{\mathrm{C}}+49 \mathrm{H} \\
& \quad \rightarrow \mathrm{C}_{6} \mathrm{~A}_{3} \mathrm{~S}_{32}+2 \mathrm{C}_{4} \mathrm{~A}_{\mathrm{C}_{0.5}} \mathrm{H}_{12} \\
& X\left(\mathrm{C}_{4} \mathrm{~A} \overline{\mathrm{C}} \mathrm{H}_{11}\right)+Y\left(\mathrm{C}_{4} \mathrm{~A} \overline{\mathrm{S}} \mathrm{H}_{12}\right)+Z(\mathrm{CH}) \\
& \rightarrow \frac{Y}{3}\left(\mathrm{C}_{6} \mathrm{~A}_{\mathrm{S}_{3}} \mathrm{H}_{32}\right)+\frac{2}{3}(X+Z)\left(\mathrm{C}_{4} \mathrm{AC}_{0.5} \mathrm{H}_{12}\right) z+\frac{Z}{3} \mathrm{CH}
\end{aligned}
$$

If reductions in the portlandite content are related to the formation of $\mathrm{Hc}$, such formation should be accompanied by a reduction in $\mathrm{CaCO}_{3}$ content. Figure 4 shows DTG curves for neat $\mathrm{OPC}$, and systems containing $15 \% \mathrm{CACl}$ or $15 \%$ CAC2 after $90 \mathrm{~d}$ of hydration under limestone-deficient conditions. It can be seen that independent of the type of CAC used, the $\mathrm{CH}$ and $\mathrm{CaCO}_{3}$ contents decrease, which is accom- 


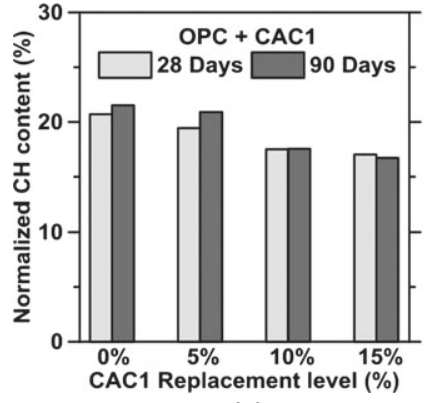

(a)

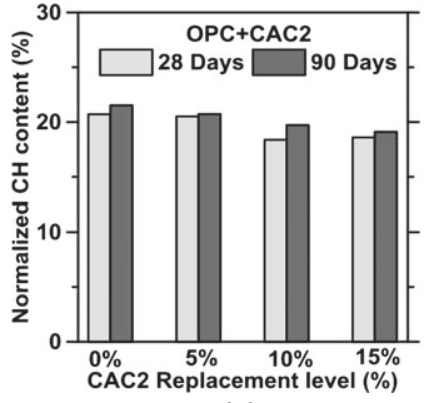

(b)

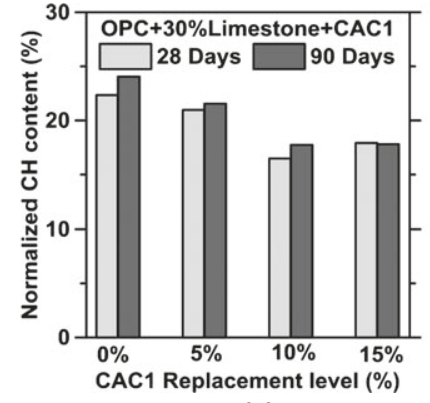

(c)

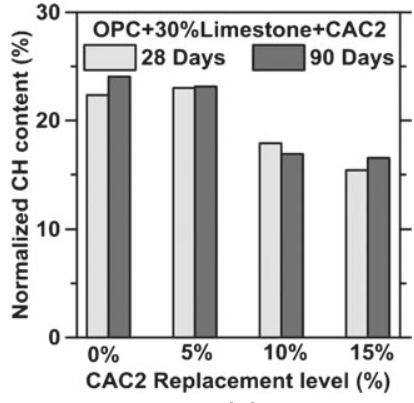

(d)

Fig. 3. The normalized portlandite contents for cementitious mixtures with varying levels of OPC replacement by: (a) CAC1 and (b) CAC2. (c and d) Show the normalized portlandite contents for mixtures with $30 \%$ limestone dosed by replacement of OPC and varying levels of additional replacement by: (c) CAC1 and (d) CAC2. The portlandite contents were determined by thermogravimetric analysis (TGA/DTG) and normalized by the OPC content of a mixture.

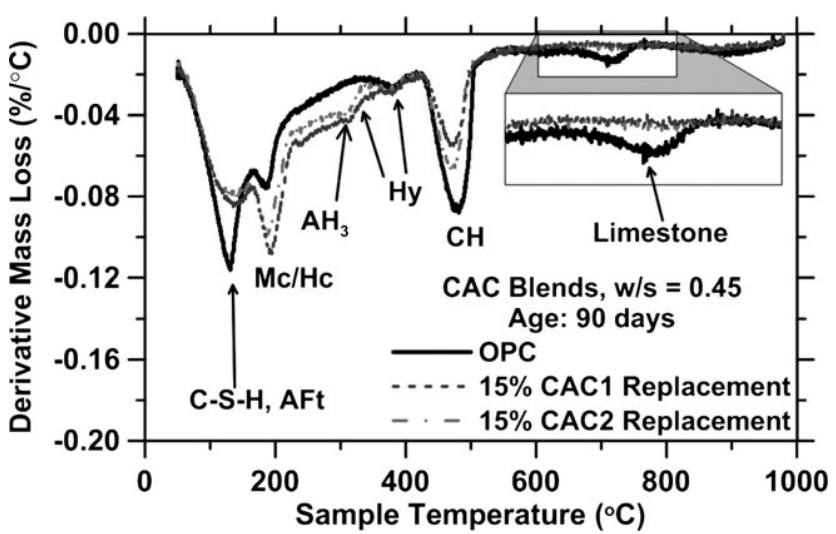

Fig. 4. Representative DTG traces for the neat OPC mixture and systems wherein $15 \%$ (by mass) of the OPC is replaced by either $\mathrm{CAC} 1$ or $\mathrm{CAC} 2$, respectively.

panied by an increase in the peak area (quantity) corresponding to the carbonate-AFm $(\mathrm{Mc} / \mathrm{Hc})$ phases. A small amount of a hydrogrossular phase $\mathrm{Ca}_{3} \mathrm{Al}_{2}\left(\mathrm{SiO}_{4}\right)_{3-x}(\mathrm{OH})_{4 x}$ is also detected. It is important to note that decomposition temperatures for the hydrogrossular phases (Hy) range between $315^{\circ} \mathrm{C}$ and $360^{\circ} \mathrm{C}$ as the Si-content alters decomposition temperatures. ${ }^{40}$ A quantity of $\mathrm{AH}_{3}$ was identified by TGA (but not XRD or GEMS calculations) and is believed to precipitate to allocate the excess aluminum present in the system. The lack of X-ray reflections (and GEMS prediction) associated with $\mathrm{AH}_{3}$ is estimated to be on account of its poor crystallinity, ${ }^{51}$ and/or a nonstoichiometric composition which would result in untabulated thermochemical (solubility) data and thus lack of means to consider this phase in the calculations.

Figure 5 shows XRD patterns for the neat OPC mixture, the mixture in which $30 \%$ of the OPC is replaced by fine limestone, and $\mathrm{OPC}-\mathrm{CAC}$ blends for limestone-deficient (i.e., with only limestone intrinsic to the OPC) and excess conditions, respectively, after $90 \mathrm{~d}$ of hydration. It is noted that $\mathrm{Mc}$ is the only $\mathrm{CO}_{3}-\mathrm{AFm}$ phase present in the neat OPC mixture, and OPC mixture in which $30 \%$ of the OPC is replaced by limestone. On the other hand, both the OPC$\mathrm{CAC}$ and $\mathrm{OPC}-\mathrm{CAC}-$ limestone blends show the presence of $\mathrm{Hc}$, in addition to $\mathrm{Mc}$ in all mixtures. While $\mathrm{Hc}$ is dominant in the former, $\mathrm{Mc}$ is dominant in the latter. These observations are in agreement with previous studies in which $\mathrm{Mc}$ is noted to be dominant in limestone excess compositions. ${ }^{6,36,37,52-54}$

In CAC systems containing a small quantity of limestone, that is, with no additional limestone added, Hc exists as the major AFm phase. This becomes more pronounced for

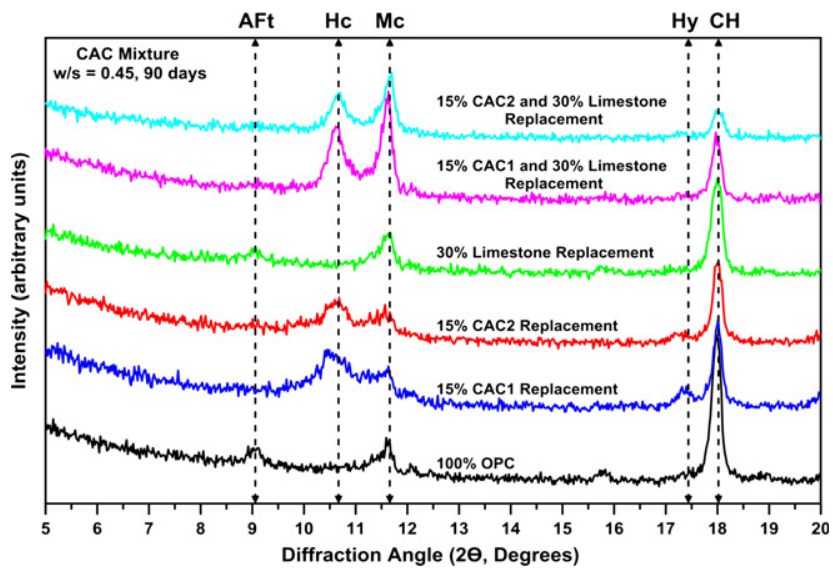

Fig. 5. Representative XRD patterns for the plain OPC, limestone enriched (30\% OPC replacement by limestone) and CAC enriched mixtures composed for limestone deficient and excess conditions. Here: Hc (hemicarboaluminate), Mc (monocarboaluminate), $\mathrm{CH}$ (portlandite), $\mathrm{AFt}$ (ettringite) and $\mathrm{Hy}$ (hydrogrossular). All enrichments are carried out by replacement of OPC by an aluminous source, and/or limestone.

higher CAC contents, that is, $\geq 10 \%$ (by mass of binder), given the aluminum-rich and the carbonate-deficient nature of these systems (e.g., $0.086<\mathrm{CO}_{2} / \mathrm{Al}_{2} \mathrm{O}_{3}<0.154$, mass ratio). In spite of the passage of time, a substantial quantity of unreacted limestone is present in systems that contain excess limestone. Based on QXRD analysis at $90 \mathrm{~d}$, only around $20 \%-36 \%$ of the limestone initially present, had reacted in the excess limestone-CAC systems, with increasing limestone consumption for higher levels of CAC $(15 \%)$ in the binder. Limestone consumption ranged between $21 \%$ and $27 \%$ as assessed by TGA at $90 \mathrm{~d}$. It should be noted that the portlandite content reduces as the CAC content in the binder is increased, an observation which is consistent with the increase in Hc formed in the system. The main diffraction peak corresponding to AFt, predicted to exist in excess limestone conditions (as seen in the thermodynamic simulations), is likely diminished due to the nature of the solvent exchange procedure (using IPA) used to arrest hydration-which is known to reduce the crystallinity of the AFt phase.

Strätlingite is not observed in any of the studied systems, based on lack of X-ray reflections. Given the presence of portlandite, it is unlikely that these two phases would coexist, ${ }^{55,56}$ though this condition is not strict, and a strätlingite precursor of poor crystallinity may well exist herein. ${ }^{57}$ The CACs themselves show different levels of reaction, with CAC1 (at 15\% dosage, by mass) showing a degree of reaction on the order of $86.6 \%$ and $100 \%$ by $90 \mathrm{~d}$ for the 
deficient and excess limestone blends, respectively. On the other hand, CAC2 never exceeds $59 \%$ reaction even under excess limestone conditions. This is because, in anhydrous form, CAC2 contains $48 \% \quad \mathrm{Al}_{2} \mathrm{O}_{3}$ (corundum), a substance which remains inert in cementitious environments. ${ }^{18}$ The difference in the degree of reaction of $\mathrm{CAC1}$, whether or not excess limestone is present is associated with water availability, which would be higher in the latter, than former case (e.g., see Ref. [59] for the effects of water availability on CAC hydration). These are indications of how the nature of the aluminum source and not just the aluminum content itself is relevant in favoring carbonaceous reactions.

To better explain the experimental data, thermodynamic simulations were carried out by fixing the degree of hydration $(\mathrm{DoH})$ of the OPC, and incrementally allowing the CAC to react. Figure 6 shows volumetric phase assemblages calculated using GEMS for binder systems containing $\mathrm{OPC}+15 \% \mathrm{CAC} 1$ or $\mathrm{OPC}+15 \% \mathrm{CAC} 2$ (by mass) in limestone deficient or limestone excess conditions. In systems containing only OPC and CAC (and limestone intrinsic to the OPC, but not additional limestone), $\mathrm{Hc}$ is the dominant AFm phase that exists, though a smaller quantity of Mc may also coexist. The hydrogrossular phases are predicted to exist only in limestone-deficient systems. As expected, the limestone intrinsic to the OPC is fully consumed for the degree of CAC reaction relevant herein. These observations are in agreement with the XRD and TGA data (Figs. 4 and 5).

When excess limestone is present, Mc is predicted to exist, as the singular AFm phase. This is in agreement with experimental data except when excess limestone may be present at larger CAC contents (i.e., around $10 \%$ and $15 \%$, by mass). In such cases, Hc and Mc are noted to coexist (see XRD patterns in Fig. 5), in contrast to the simulations which indicate the existence of Mc. It is speculated that this happens on the account of slow dissolution of limestone which maintains $\left[\mathrm{CO}_{3}{ }^{2-}\right] /\left[\mathrm{OH}^{-}\right]$levels buffered at a value that is less than optimum for the formation of the Mc exclusively, or the slow kinetics of the Hc-to-Mc conversion. A substantial quantity of unreacted limestone persists in limestone excess systems in spite of a favorable binder chemistry, that is, a aluminum, calcium, and carbonate ion-rich environment. It is postulated that if the quantity of CAC reacted was hypothetically elevated, notably in the case of CAC2, whereas the quantity of Mc formed would increase, unreacted limestone would continue to persist. This indicates that while the composition of CACs, and the overall binder, should favor carbonaceous reactions; the reality is different with only a small amount of limestone actually reacting. For example, the TGA data indicates that at most $27 \%$ of the limestone available (i.e., around $8.7 \%$ of the $32.4 \%$ limestone present initially, by mass) reacts in the most favorable case under limestone excess conditions, when a CAC is provisioned as an aluminous source.

Kumar et al. ${ }^{58}$ quantified the aqueous dissolution rates of limestone, using vertical scanning interferometry across a range of solution pH's. ${ }^{58}$ They observed that the dissolution rate decays with $\mathrm{pH}$, approaching a near horizontal asymptote for $\mathrm{pH}$ levels $>12 .^{58}$ This may suggest that the low reactivity (i.e., the dissolution rate) of limestone is likely the rate-limiting step in $\mathrm{CO}_{3}-\mathrm{AFm}$ formation. This comment is made as if limestone were indeed readily soluble, the release of the $\mathrm{CO}_{3}{ }^{2-}$ species, and their combination with the $\mathrm{Ca}^{2+}$ and $\mathrm{Al}(\mathrm{OH})_{4}{ }^{-}$species provided by the CAC (and OPC) would ensure rapid/enhanced limestone reaction. This idea is strengthened by recent observations of a CAC reacting with $\mathrm{Ca}\left(\mathrm{NO}_{3}\right)_{2}$, a readily, and highly soluble calcium salt. In this case, the formation of a $\mathrm{NO}_{3}-\mathrm{AFm}$ phase is rapid and abundant-unlike the circumstance observed with $\mathrm{CaCO}_{3}$

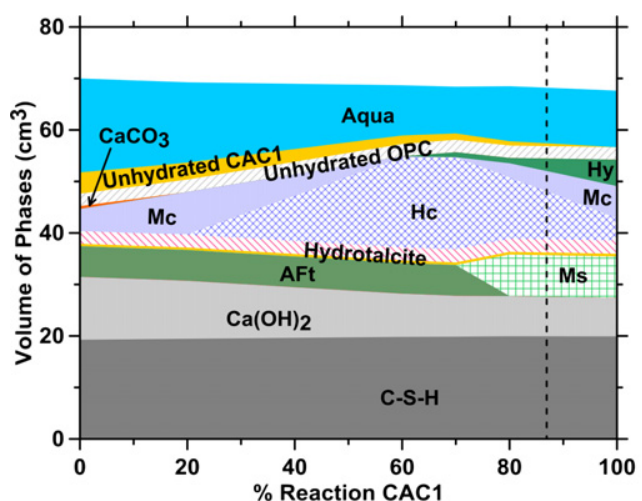

(a)

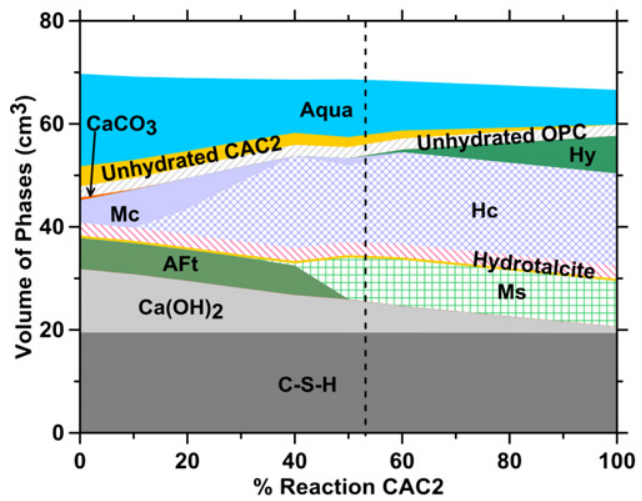

(c)

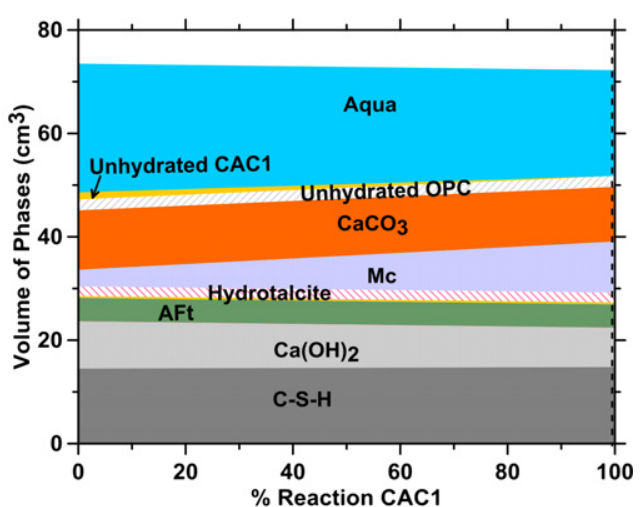

(b)

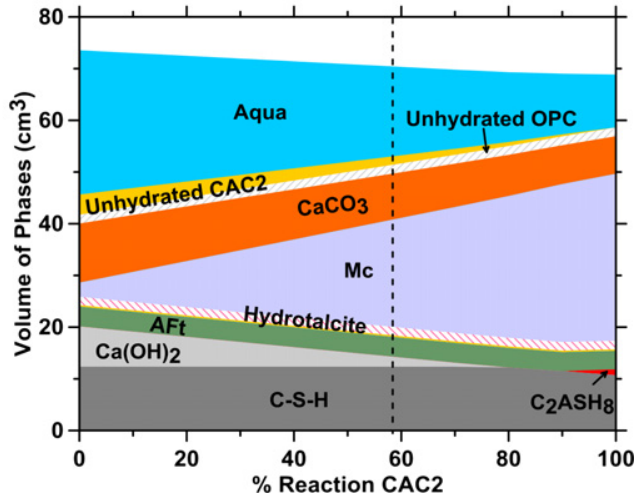

(d)

Fig. 6. Phase assemblages estimated using GEMS for: (a) 15\% CAC1 replacement, (b) $15 \%$ CACl and additional 30\% limestone replacement, (c) $15 \%$ CAC2 replacement and (d) $15 \%$ CAC2 and additional 30\% limestone replacement. All replacements were carried out by reducing the quantity of OPC on a mass basis. Monosulfoaluminate (Ms), ettringite (AFt), monocarboaluminate (Mc), hemicarboaluminate (Hc), strätlingite $\left(\mathrm{C}_{2} \mathrm{ASH}_{8}\right)$, hydrogrossular $(\mathrm{Hy})$ and hydrotalcite $\left(\mathrm{M}_{4} \mathrm{AH}_{10}\right)$ are denoted. The dashed lines locate the estimated phase assemblage after $90 \mathrm{~d}$, based on the degree of CAC reaction as estimated by QXRD. 
additions, when the formation of $\mathrm{Hc} / \mathrm{Mc}$ is far more limited, in spite of excess $\mathrm{CaCO}_{3}$ being present. ${ }^{59-61}$ Therefore, it appears as though the combination of both, binder chemistry, and the low limestone dissolution rates are responsible for limited $\mathrm{CO}_{3}-\mathrm{AFm}(\mathrm{Hc} / \mathrm{Mc})$ formation in blended binder systems. It should be highlighted that for the extent of CAC hydration estimated herein, a Hy (hydrogrossular phase) is predicted to exist in the limestone-deficient CAC1 [i.e., 15\% CAC1, Fig. 6(a)] system but not in the analogous CAC2 system [Fig. 6(c)] which is in agreement with XRD patterns shown in Fig. 5. It is observed that the conversion of $\mathrm{AFt}$ into Ms does not occur in systems with excess limestone, whereas in the limestone-deficient systems, Ms is stabilized after limestone uptake in $\mathrm{Hc} / \mathrm{Mc}$ is complete, as recognized previously [see Figs. 6(a) and (c)]. ${ }^{16}$ It is important to note that, even though, $\mathrm{Ms}$ and $\mathrm{AFt}$ are predicted to exist (at varying levels) by thermodynamic calculation, these phases are slightly, if at all, identified by XRD. This is likely on account of the solvent exchange procedure used, which compromises the structure of AFt (rendering it X-ray amorphous ${ }^{20,62}$, and the potential formation of a $\mathrm{CO}_{3}-$ $\mathrm{SO}_{4}-\mathrm{AFm}$ ordered compound in lieu of Ms as discussed further in Section III(3).

\section{(2) Influence of Metakaolin Additions}

As shown in Fig. 2, the replacement of OPC by metakaolin consistently improves strength. Such beneficial effects of metakaolin addition, both with and without excess limestone have also been highlighted by Antoni et al. ${ }^{28}$ and Vance et al., ${ }^{63,64}$ and attributed to the pozzolanic character of metakaolin, and the formation of the $\mathrm{Hc} / \mathrm{Mc}$ phases. This is significant in that in spite of very substantial reductions in the $\mathrm{CF}$, mechanical properties near equivalent to the neat OPC mixtures can be achieved in metakaolin containing mixtures. For example, a mixture containing 60\% OPC, 10\% metakaolin and $30 \%$ limestone $(\mathrm{CF}=0.58$, see Fig. 2) shows a compressive strength $\approx 80 \%$ of the neat OPC mixture in spite of $42 \%$ reduction in the OPC content.

Figure 7 shows representative DTG traces at $90 \mathrm{~d}$, and the portlandite content normalized by the cement factor $(\mathrm{CF})$ for the metakaolin containing mixtures. It was observed that portlandite contents of a given mixture decrease with increasing OPC replacement by metakaolin, even when dilution is accounted for. This is as expected due to the pozzolanic nature of metakaolin, which consumes lime to form a lower $\mathrm{Ca} / \mathrm{Si}, \mathrm{C}-\mathrm{S}-\mathrm{H}$ phase. Formation of such additional $\mathrm{C}-\mathrm{S}-\mathrm{H}$ ensures that metakaolin containing mixtures show reduced decreases in their compressive strength, in spite of a substantial level of OPC replacement.

Figure 8 shows XRD patterns for the metakaolin containing mixtures after $90 \mathrm{~d}$ of hydration. Mc exists as the dominant phase, when excess limestone is added. When only

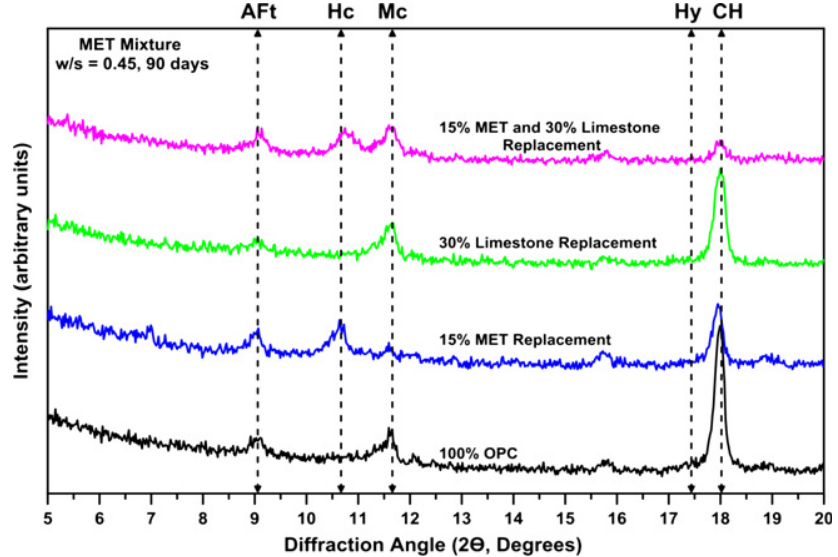

Fig. 8. Representative XRD patterns for the plain (100\% OPC), limestone enriched $(30 \%$ OPC replacement by limestone) and MET enriched mixtures composed for limestone deficient and excess conditions. Here: Hc (hemicarboaluminate), Mc (monocarboaluminate), $\mathrm{CH}$ (portlandite), $\mathrm{AFt}$ (ettringite), and $\mathrm{Hy}$ (hydrogrossular). All enrichments are carried out by replacement of OPC.

limestone intrinsic to the OPC is present, Mc is stabilized only when metakaolin is absent. When metakaolin replaces OPC, in increasing proportion, $\mathrm{Hc}$ is stabilized as the dominant phase. This is in agreement with the observations of Antoni et al. and Vance et al. ${ }^{28,64}$ The contents of the $\mathrm{CO}_{3}$ $\mathrm{AFm}$ (i.e., $\mathrm{Hc} / \mathrm{Mc}$ ) phases, reflect trends in limestone consumption (see Figs. 7 and 8). A higher quantity of the $\mathrm{CO}_{3}-\mathrm{AFm}$ 's forms with increasing metakaolin content, and when excess limestone is present. While these trends follow evolutions in the equivalent $\mathrm{CO}_{2} / \mathrm{Al}_{2} \mathrm{O}_{3}$ ratio, limestone consumption is only partial, once again, likely on account of the low dissolution rate of limestone. In spite of the near consumption of portlandite, for example, in the $15 \%$ metakaolin mixture containing excess limestone, strätlingite is not observed in the XRD patterns. Small quantities of ettringite are present in both the deficient and excess limestone mixtures, wherein the release of sulfate ions, due to preferred $\mathrm{CO}_{3}{ }^{2-}$ ion uptake into the AFm phase, stabilizes ettringite in these systems.

Figure 9 shows volumetric phase assemblages, calculated using GEMS, for $15 \%$ OPC replacement by metakaolin in either limestone deficient or excess conditions. These systems show a degree of metakaolin reaction of $37 \%$ and $32 \%$, in limestone deficient and excess cases, respectively, [see Section II(6) for how the degree of metakaolin reaction is ascertained]. The degree of metakaolin reaction is a function of its dosage, wherein lower dosages correspond to higher degrees of reaction. In general, the degree of metakaolin reaction ranges between $32 \%$ and $75 \%$ as assessed by the portlandite-

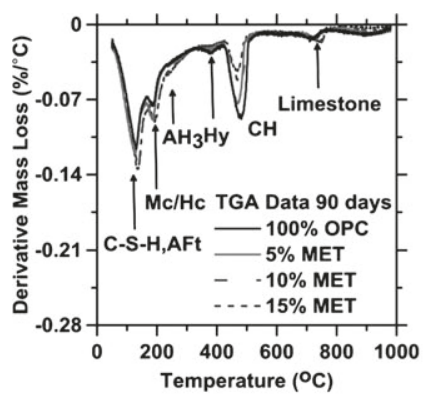

(a)

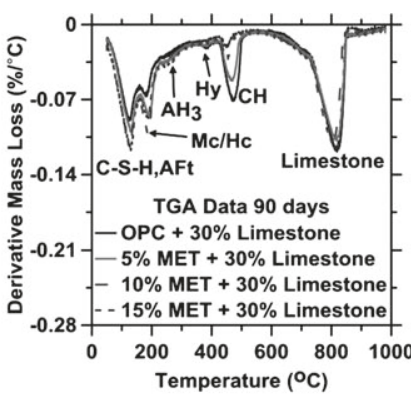

(b)

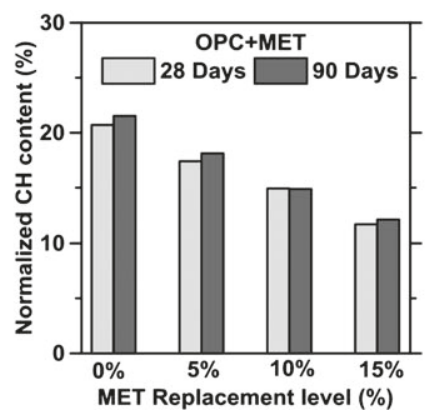

(c)

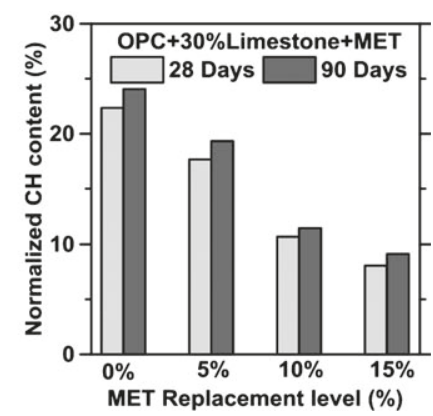

(d)

Fig. 7. Representative DTG curves of OPC mixtures for: (a) $0 \%$ to $15 \%$ MET replacement, (b) $0 \%$ to $15 \%$ MET replacement with additional $30 \%$ of limestone dosed by OPC replacement. The normalized (by CF) portlandite contents for OPC mixtures for: (c) $0 \%$ to $15 \%$ MET replacement, (b) $0 \%$ to $15 \%$ MET replacement with additional $30 \%$ of limestone dosed by OPC replacement. The portlandite contents were determined by thermal analysis (TGA/DTG). All replacements were carried out by reducing the quantity of OPC on a mass basis. 


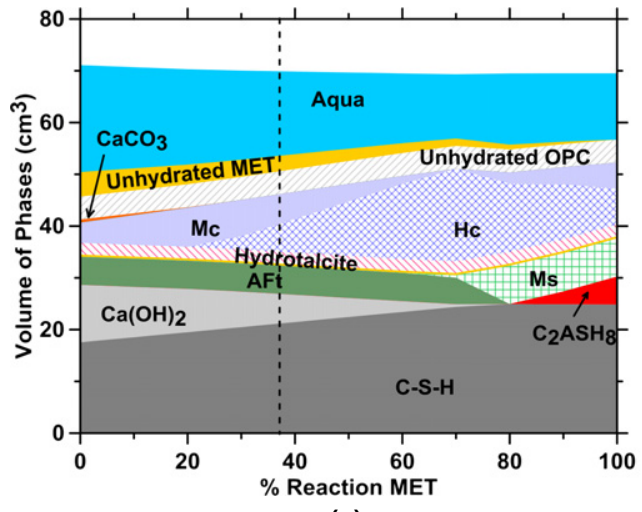

(a)

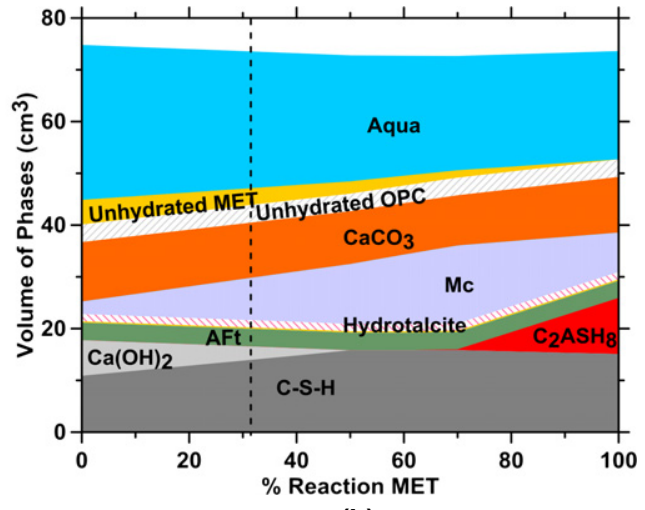

(b)

Fig. 9. Phase assemblages estimated using GEMS by incremental reaction of MET for: (a) $15 \%$ MET and (b) $15 \%$ MET and additional $30 \%$ limestone replacement of OPC after $90 \mathrm{~d}$ of hydration. Monosulfoaluminate (Ms), ettringite (AFt), monocarboaluminate (Mc), hemicarboaluminate $(\mathrm{Hc})$, strätlingite $\left(\mathrm{C}_{2} \mathrm{ASH}_{8}\right)$, and hydrotalcite $\left(\mathrm{M}_{4} \mathrm{AH}_{10}\right)$ are denoted. The dashed lines locate the estimated phase assemblage and MET degree of hydration, after $90 \mathrm{~d}$, based on the portlandite match point from TGA data as discussed in the text.

matching criterion, from higher $(15 \%)$ to lower $(5 \%)$ MET dosages, respectively. The simulations are in agreement with experimental indications of phase assemblages, except for specific aspects which are discussed further below.

In contrast to the other aluminous agents, the pozzolanic nature of metakaolin ensures that its increasing reaction consumes lime and increases the quantity of $\mathrm{C}-\mathrm{S}-\mathrm{H}$ formed, albeit, of a lower $\mathrm{Ca} / \mathrm{Si}$ ratio $^{65}$ and potentially also higher Al-substitution. ${ }^{42,66}$ In agreement with XRD data, both $\mathrm{C}_{2} \mathrm{ASH}_{8}$ and $\mathrm{Hy}\left(\mathrm{C}_{3} \mathrm{AS}_{0.02} \mathrm{H}_{5.96}\right)$ are not predicted to form for the levels of metakaolin reaction seen in this study. In contrast to these observations, XRD data of Antoni et al. showed the presence of $\mathrm{C}_{2} \mathrm{ASH}_{8}$ and portlandite coexisting with each other. ${ }^{28}$ While this is a violation of thermodynamic phase relations established by Damidot et al., ${ }^{67}$ it may be on the account of higher metakaolin contents used in their study, or due to inhomogeneous reaction zones. This discrepancy could, however, also be on account of uncertainties in determination of solubility data, small variations in which could alter stability fields dramatically. For example, as noted in the simulations shown herein (Fig. 9), strätlingite is predicted to form only when portlandite is fully consumed due to: (i) pozzolanic reactions, and/or (ii) to form Hc.

When only limestone intrinsic to the OPC is present [see Fig. 9(a)], at low levels of metakaolin reaction, Mc (monocarboaluminate) is stabilized. With the passage of time and with increase in metakaolin reaction, the phase relations change and $\mathrm{Hc}$ (hemicarboaluminate) is dominant with $\mathrm{Mc}$ existing as the minor $\mathrm{CO}_{3}-\mathrm{AFm}$ phase. For the degree of metakaolin reaction ascertained herein, $\mathrm{Mc}$ and $\mathrm{Hc}$ appear to exist in equivalent volumetric quantities, though by mass this would translate to a larger quantity of Mc (the denser $\mathrm{CO}_{3}$-AFm phase $)^{68,69}$ in contrast to XRD data shown in Fig. 8. While this may indicate that the ascertained degree of metakaolin reaction is lower than reality, it may also suggest kinetic restraint in the formation of $\mathrm{Hc}$, from $\mathrm{Mc}, \mathrm{Ms}$ and portlandite (or vice-versa depending on the environment). When excess limestone is present, Mc is the dominant AFm phase [Fig. 9(b)]. This is once again in contrast to the XRD observations in Fig. 8, where even under limestone excess conditions, when $(15 \%)$ metakaolin is present, $\mathrm{Hc} / \mathrm{Mc}$ coexist; reasons for which are discussed above [Section III(1)]. For all degrees of metakaolin reaction, a large quantity of limestone remains unreacted, ensuring only modest levels of $\mathrm{Hc} / \mathrm{Mc}$ formation. This leads to the conclusion that the compensation in the mechanical properties (see Fig. 2), produced by the combined replacement of OPC, by both limestone and metakaolin, is dominantly on account of the pozzolanic nature of metakaolin and less so due to the formation of $\mathrm{CO}_{3}-$ AFm phases. This has important compositional impacts on reducing OPC use, and the selection of suitable OPC replacement agents.

\section{(3) Influence of Hydratable Alumina Additions}

Blended cementitious formulations containing HA show distinct trends in compressive strength whether or not excess limestone is present. For example: as shown in Fig. 2, in the absence of excess limestone, HA containing mixtures show reductions in strength with increasing HA dosage, lying below the dilution line. However, when excess limestone is present, the trend inverts, with beneficial/synergistic effects of HA additions being noted. For example: mixtures containing 55\% OPC, $30 \%$ limestone and $15 \%$ HA $(\mathrm{CF}=0.53)$ show compressive strengths of $\approx 70 \%$ of a neat OPC formulation, that is, significantly higher than that would be expected based on their extent of OPC replacement $(47 \%$ reduction in the OPC content). This strength recovery is on the account of the formation of AFm-type phases and is explained further below.

Figure 10 shows DTG traces of mixtures containing HA, and the portlandite contents of HA-dosed mixtures. The portlandite content is normalized by the cement factor $(\mathrm{CF})$ to account for dilution. Independent of the presence of excess, or low levels of limestone, portlandite content decreases with an increase in the HA content. This is on account of the consumption of portlandite, to form $\mathrm{Hc}$, as noted in the case of CAC-dosed formulations. It is important to note that the extent of $\mathrm{Hc}$ or Mc formed in HA systems exceeds that of CAC or MET systems, based on TGA, and $\mathrm{QXRD}^{\mathrm{e}}$ estimations. This idea is strengthened by the QXRD data which reveals no suppression in the OPC reaction, whether or not any HA (or quartz which is an inert filler) is present.

The DTG traces reveal that the addition of HA results in increases in (with increasing HA dosage): (i) the quantity of $\mathrm{AH}_{3}$ formed, (ii) the quantity of $\mathrm{Hc} / \mathrm{Mc}$ formed, and a concurrent decrease in the unreacted limestone content and (iii) the quantity of hydrogrossular (Hy) phases formed. This indicates that HA serves as a reactive source of aluminum in such blends. It was determined by TGA quantifications that in limestone excess blends between $24 \%$ and $32 \%$ of the total limestone initially present (mass basis) is consumed by $90 \mathrm{~d}$. This level of limestone consumption, higher than that

${ }^{\mathrm{e}}$ While quantitative XRD with Rietveld refinement can provide accurate values of the residual (or initial) quantities of crystalline phases, quantifications of less ordered phases such as $\mathrm{Hc}$ and $\mathrm{Mc}$ are less precise. This is not a limitation of QXRD techniques generically, but rather a result of the nature of measurements, and the refinement procedures implemented herein. For example, see the recent implementation of the PONCKS method by Snellings et al. as applicable to disordered phases. ${ }^{46}$ 


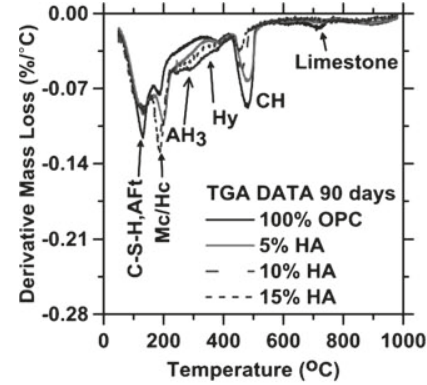

(a)

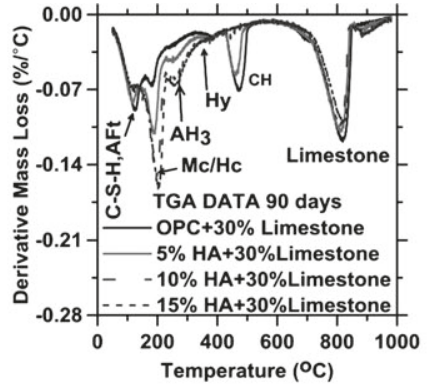

(b)

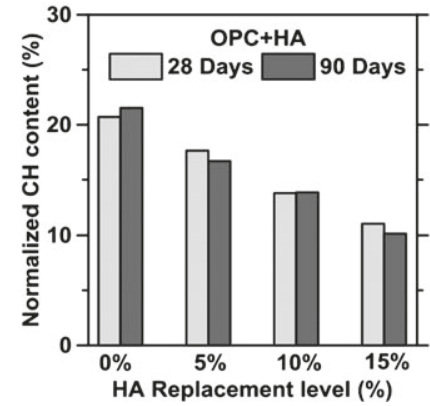

(c)

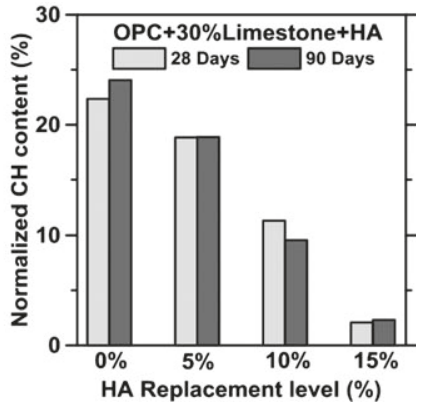

(d)

Fig. 10. Representative DTG curves for OPC mixtures for: (a) $0 \%-15 \%$ HA replacement, (b) $0 \%-15 \%$ HA replacement with additional $30 \%$ of limestone dosed by OPC replacement. The normalized (by CF) portlandite contents for OPC mixtures for: (c) $0 \%-15 \%$ HA replacement, (d) $0 \%-15 \%$ HA replacement with additional $30 \%$ of limestone dosed by OPC replacement. The portlandite contents were determined by thermal analysis (TGA/DTG). All replacements were carried out by reducing the quantity of OPC, by HA and/or limestone, on a mass basis.

noted for the other aluminous agent containing blends (see fig. 14 below), explains the enhanced formation of $\mathrm{CO}_{3-}$ AFm phases (Hc and/or Mc) in HA containing systems.

XRD observations (Fig. 11), in agreement with TGA data, indicate that the portlandite content of a given mixture, in both limestone deficient and excess cases, reduces with HA dosage. In the former case, limestone is near completely consumed by $90 \mathrm{~d}$. But when excess limestone is present, a quantity of unreacted limestone persists. $\mathrm{Mc}$ exists as the dominant $\mathrm{CO}_{3}-\mathrm{AFm}$ phase, though in coexistence with $\mathrm{Hc}$ in cases when excess limestone is present (Fig. 11). When the system is limestone deficient, Mc is stabilized if no $\mathrm{HA}$ is added. As the HA dosage increases, $\mathrm{Hc}$ is the dominant phase, and is in fact the only carbonate-AFm that exists at $15 \%$ HA dosage, as observed also by Whittaker et al. ${ }^{70}$ Abundance of the $\mathrm{CO}_{3}-\mathrm{AFm}$ phases (i.e., both $\mathrm{Hc}$ and $\mathrm{Mc}$ ), increases with increments of $\mathrm{HA}$ and limestone. While strätlingite is not seen, a hydrogrossular phase is stabilized, especially at higher HA contents in limestone-deficient systems. Lack of x-ray reflections for strätlingite, and $\mathrm{AH}_{3}$ is believed to be due to similar factors as explained in Section III(2). Monosulfoaluminate (Ms) is not seen, perhaps due to the nature of solvent exchange, or the potential formation of a $\mathrm{CO}_{3}-\mathrm{SO}_{4}-\mathrm{AFm}$ phase as discussed below.

Baquerizo et al. ${ }^{71}$ investigated the water content of Ms when exposed to changes in relative humidity $(\mathrm{RH})$ and temperature and showed that a reduction in RH (i.e., drying) impacts the water content and the interplanar spacing (d) and the position of the main diffraction peak. Such a shift in the main peak of Ms toward higher $2 \theta$ angles potentially caused by solvent exchange (drying) would result in an overlap with the $\mathrm{Hc}$ signature. Further, though the literature does not indicate a solid-solution between $\mathrm{CO}_{3}-\mathrm{AFm}$ and $\mathrm{SO}_{4}-\mathrm{AFm}{ }^{14}$ recent studies conducted by Renaudin et al. ${ }^{72}$ indicate the existence of new phase, $\left[\mathrm{Ca}_{2} \mathrm{Al}(\mathrm{OH})_{6}\right] \cdot\left[\left(\mathrm{SO}_{4}\right)_{1 / 2-x} \cdot\left(\mathrm{CO}_{3}\right)_{x / 2} \cdot n \mathrm{H}_{2} \mathrm{O}\right.$ (i.e., a $\left.\mathrm{CO}_{3}-\mathrm{SO}_{4}-\mathrm{AFm}\right) ;$ an ordered compound containing both carbonate and sulfate ions in its structure. Due to the lack of precise structural, compositional, and thermodynamic descriptions this phase could not be identified or predicted in the present study. Nevertheless, it should not be disregarded as it is believed to have the potential to form and persist. In fact if $\mathrm{CO}_{3}-\mathrm{SO}_{4}-\mathrm{AFm}$ did form, its main diffraction peak at $2 \theta$ values of $\approx 11^{\circ}$ could: (a) obscure $\mathrm{Hc}$ identification as $\mathrm{Hc}$ has a main peak at similar $2 \theta$ location or (b) suggest that $\mathrm{Hc}$ and $\mathrm{Ms}$ formation is prevented at the expense of the $\mathrm{CO}_{3}-\mathrm{SO}_{4}-\mathrm{AFm}$ phase, which may indeed be thermodynamically more stable.

Figure 12 shows the volumetric phase assemblages predicted by GEMS, for blends containing 15\% HA under either limestone deficient, or excess conditions. In these calculations, the degree of OPC reaction is fixed, and the extent of HA reaction varies. Based on the portlandite content determined from TGA data, the HA was assessed to have

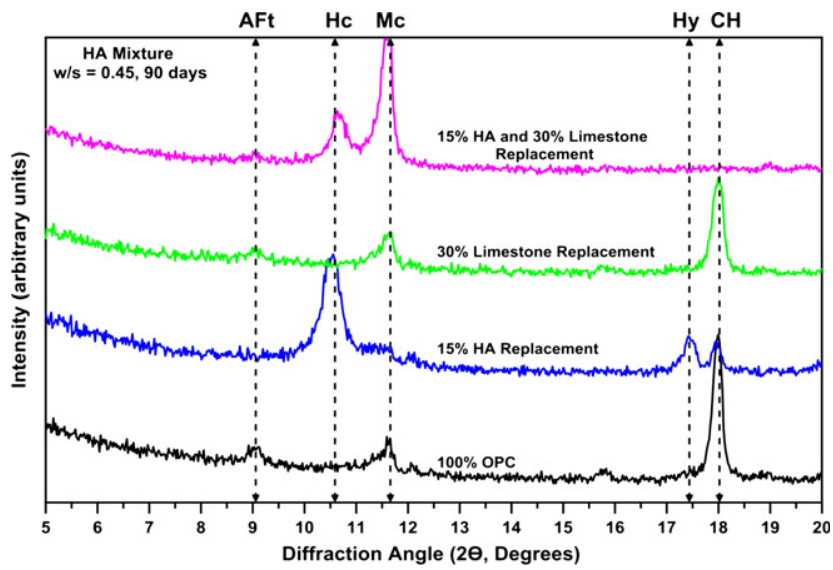

Fig. 11. Representative XRD patterns for the plain (100\% OPC), limestone enriched $(30 \%$ OPC replacement by limestone) and HA enriched mixtures composed for limestone deficient and excess conditions. Here: $\mathrm{Hc}$ (hemicarboaluminate), $\mathrm{Mc}$ (monocarboaluminate), $\mathrm{CH}$ (portlandite), AFt (ettringite), and $\mathrm{Hy}$ (hydrogrossular). All enrichments are carried out by replacement of OPC by HA and/or limestone, by mass.

reacted around $43 \%$, that is, which is the lowest degree of HA reaction across the HA dosages considered. The degree of reaction of the HA across all dosages ranges between $43 \%$ and $93 \%$ and $50 \%-63 \%$ for limestone deficient and excess conditions, respectively. The slight formation of a hydrogrossular phase $\left(\mathrm{C}_{3} \mathrm{AS}_{0.15} \mathrm{H}_{5.97}\right)$ is predicted under limestone-deficient conditions as shown in Fig. 12(a).

The simulations highlight that with increasing HA dosage and its reaction, $\mathrm{Hc}$ becomes dominant with Mc existing as the minor $\mathrm{CO}_{3}-\mathrm{AFm}$ phase. In the presence of excess limestone and the HA, Mc is estimated to be the dominant (and singular) AFm phase [Fig. 12(b)]; but without Hc being predicted to coexist. This finding is contrary to the XRD data (see Fig. 11). This discrepancy, that is, of $\mathrm{Hc} / \mathrm{Mc}$ coexistence is explained on the basis of the slow dissolution kinetics of limestone, and potentially kinetic restraints on $\mathrm{Hc}$-to-Mc phase conversion. It is additionally speculated that with increasing $\mathrm{HA}$ dosage, the presence of Hc may also be a consequence of the large supply of aluminate $\left[\mathrm{Al}(\mathrm{OH})_{4}{ }^{-}\right]$species, which serve in a charge balancing role, and therefore suppress $\mathrm{CO}_{3}{ }^{2-}$ abundances in solution; ensuring the precipitation of $\mathrm{Hc}$, at the expense of $\mathrm{Mc} .{ }^{73}$ Substantial quantities of $\mathrm{Al}(\mathrm{OH})_{4}{ }^{-}$are ensured by the high $\mathrm{pH}$ of pore solution, the soluble $\mathrm{Na}_{2} \mathrm{O}$ content in $\mathrm{HA}$, and its amorphous nature, which renders it amenable to dissolution. ${ }^{74}$ In time, as the system converges to thermodynamic equilibrium, $\mathrm{Hc}$, is expected to convert to Mc, given the higher stability of the 


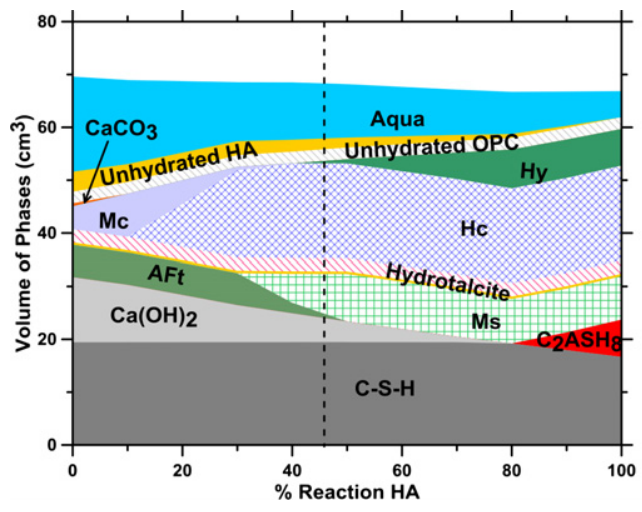

(a)

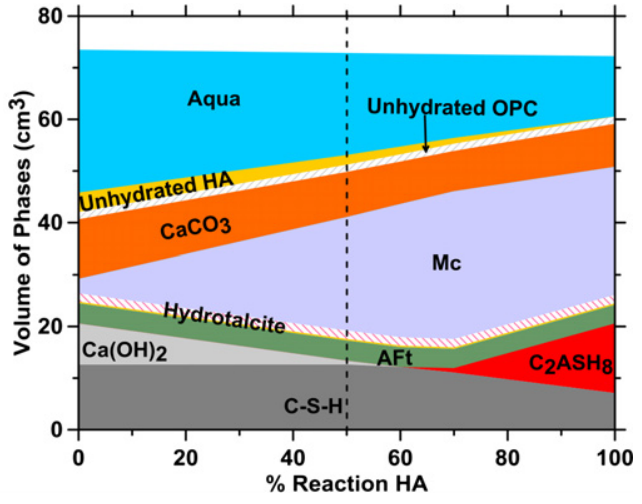

(b)

Fig. 12. Phase assemblages estimated using GEMS by incremental reaction of HA for: (a) $15 \%$ HA and (b) $15 \%$ HA and additional $30 \%$ limestone replacement of $\mathrm{OPC}$ after $90 \mathrm{~d}$ of hydration. Monosulfoaluminate (Ms), ettringite (AFt), monocarboaluminate (Mc), hemicarboaluminate $(\mathrm{Hc})$, strätlingite $\left(\mathrm{C}_{2} \mathrm{ASH}_{8}\right)$, Hydrogrossular $(\mathrm{Hy})$, and hydrotalcite $\left(\mathrm{M}_{4} \mathrm{AH}_{10}\right)$ are denoted. The dashed lines locate the estimated phase assemblage and HA degree of hydration, after $90 \mathrm{~d}$, based on the portlandite match point from TGA data as discussed in the text.

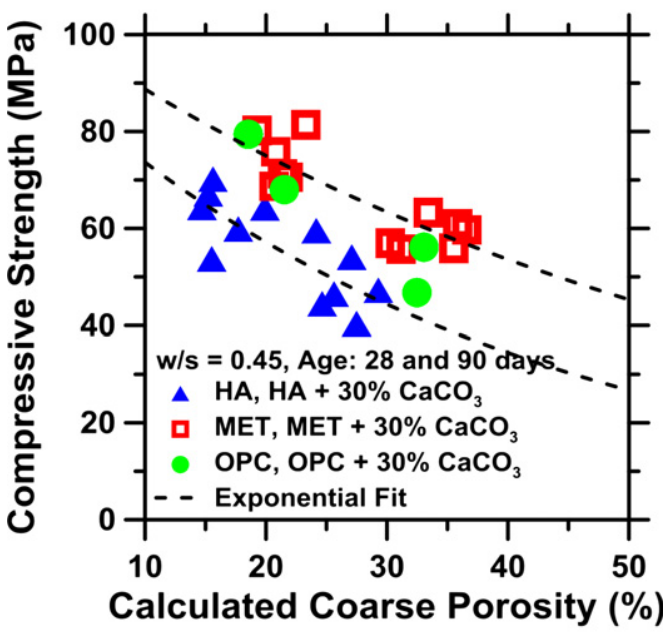

(a)

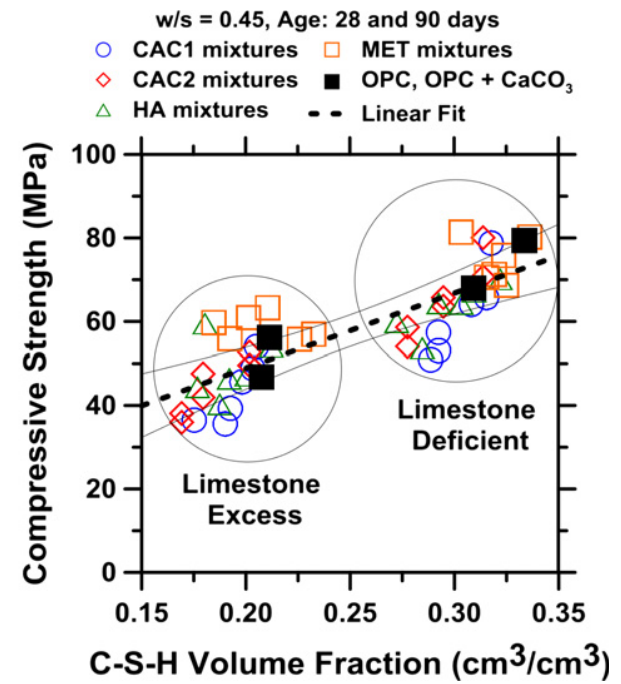

(b)

Fig. 13. (a) Calculated strength-porosity trends for cementitious blends containing HA or MET at 28 and $90 \mathrm{~d}$ of hydration and (b) The strength as a function of the $\mathrm{C}-\mathrm{S}-\mathrm{H}$ volume fraction for all the cementitious blends considered in this study.

latter as compared to the former. While a large quantity of limestone remains unreacted in the excess limestone systems [Fig. 12(b)], per unit of OPC replacement, clearly, HA is most efficient at provoking $\mathrm{CO}_{3}-\mathrm{AFm}$ phase formation. This supports the idea that unlike for metakaolin where the pozzolanic reaction allows for compensation in mechanical properties, when $\mathrm{HA}$ is added, it is the formation of $\mathrm{CO}_{3}-\mathrm{AFm}$ 's and accompanying phases (e.g., hydrogrossular) that enables strength recovery. ${ }^{75}$ This supports the original premise that so long as limestone can be rendered reactive the favorable properties of the $\mathrm{CO}_{3}-\mathrm{AFm}$ phases can be exploited to ensure near similar engineering properties (strength) as traditional OPC systems. ${ }^{64,76-78}$ This suggests an important direction of future research, that is, to identify new means to enhance the reactivity of limestone in cement systems, by mechanical or chemical activation.

\section{Correlating Phase Balances to Mechanical Properties, and Comparing Aluminous Agents}

To better correlate microstructural indicators to compressive strength, the coarse porosity (i.e., volume fraction of pore solution, at a given degree of reaction, relevant at 28 and $90 \mathrm{~d}$ ) was estimated from the GEMS simulations. ${ }^{27,79,80}$ The values of porosity thus determined were used to construct strength-porosity plots, for both the MET and HA systems. These two systems were chosen as they rendered the most promising results in terms of "strength similarity" as compared to the neat OPC formulation (i.e., with and without added limestone). Expectedly, the strength reduces with increasing porosity (i.e., decreasing CF). As seen in Fig. 13(a), the MET and HA mixtures follow two distinct trend-lines wherein at any given porosity value, HA systems show a strength which is consistently $\approx 18 \%$ lower when compared with similar MET systems. This indicates that the solid $(\mathrm{C}-\mathrm{S}-\mathrm{H})$ phases that are formed in MET systems, and the nature of their bonding is superior to HA systems from a compressive strength point of view.

More detailed analysis of the simulation datasets suggests that difference in strengths is directly linked to the amounts of $\mathrm{C}-\mathrm{S}-\mathrm{H}$ present in the system, for example, with a linear correlation between $\mathrm{C}-\mathrm{S}-\mathrm{H}$ quantity and strength being observed [Fig. 13(b)]. This suggests that while the formation of the $\mathrm{CO}_{3}-\mathrm{AFm}$ phases is able to offset the effects of dilution-strength recovery is partial at best. This is because in spite of their attractive mechanical properties, ${ }^{81,82}$ the $\mathrm{CO}_{3}-$ AFm phases are not able to provide the same mechanical performance as the $\mathrm{C}-\mathrm{S}-\mathrm{H}$ phase; albeit of varying $\mathrm{Ca} / \mathrm{Si}$ (molar) ratios. Therefore, in the context of cement factor $(\mathrm{CF})$ reduction, it is safe to say that the most effective (and 
practically easiest) means lies in joint substitution of OPC by a pozzolanic and aluminous agent, for example, metakaolin. It is important to note that since this study has evaluated only pastes, that is, mixtures devoid of fine or coarse aggregates, the influences of a pozzolanic agent on strengthening the ITZ are not accounted for. This may suggest that in mortars and concretes, where the ITZ is present, the benefits of pozzolan addition, for example, in the context of compressive strength enhancement would likely be additive to the effects noted above.

To evaluate the ability of different aluminous agents to enhance limestone reactions, Fig. 14 compares the quantity of limestone consumed, for a given dosage of an aluminous agent. It was found that the extent of limestone consumed scales in the order $\mathrm{HA}>\mathrm{CAC} 1>\mathrm{CAC} 2>\mathrm{MET}$. This trend is broadly correlated to the $\mathrm{Al}_{2} \mathrm{O}_{3}$ content available in these aluminous sources. Expectedly the quantity of $\mathrm{Hc}$ and/or $\mathrm{Mc}$ formed follows the same order, wherein MET produces the least quantity of $\mathrm{CO}_{3}-\mathrm{AFm}$ phases, and $\mathrm{HA}$, the largest quantity (Fig. 15). It is noted that limestone consumption shows a pessimum-type effect, where intermediate dosages of the aluminous agent induce the largest (relative) extents of limestone consumption; after which a plateau in limestone consumption (for HA) or decrease is noted (for CAC1, CAC2, MET); as shown in Fig. 14. This suggests that simply increasing the aluminous agent dosage does not ensure an increase in the extent of limestone reaction-but rather it depends on the type of aluminous source that is used.

It should be also highlighted that under limestone excess conditions across all aluminous agents considered, a clear

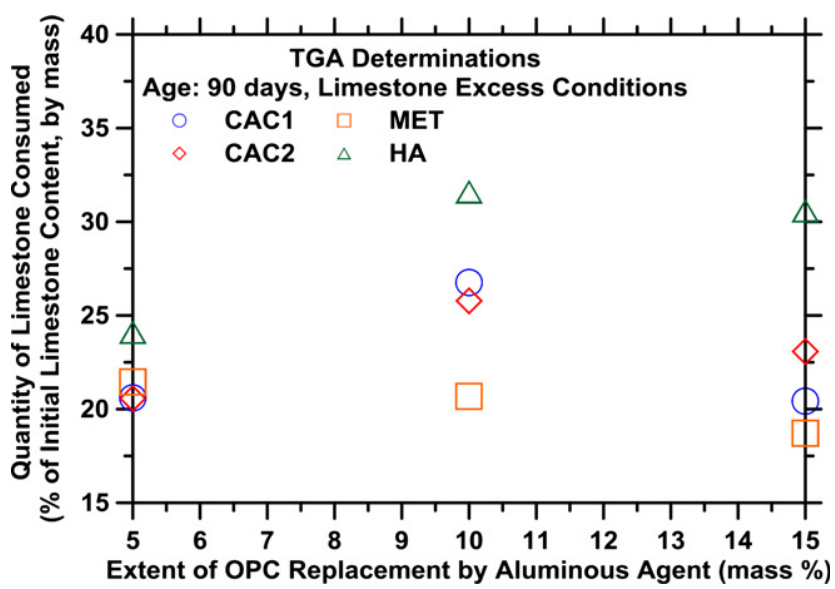

Fig. 14. The quantity of limestone consumed as a percentage of the initial quantity of limestone present (mass basis) in excess limestone systems as evaluated using thermogravimetric analysis for the range of aluminous sources considered in this study.

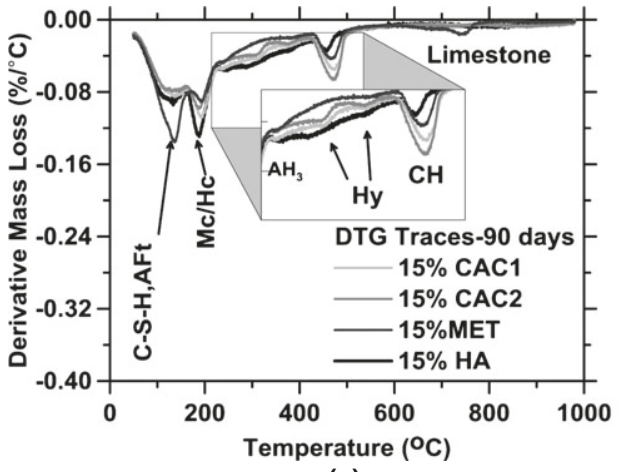

(a) thermal decomposition peak for $\mathrm{AH}_{3}$ is revealed. This indicates that the initial dissolution of limestone may not be fast enough to supply $\mathrm{CO}_{3}{ }^{2-}$ ions in a quantity required to ensure the continued formation of Mc. As a consequence, $\mathrm{Hc}$ forms and equilibrium is established between solution, and solid phases as dictated by the $\left[\mathrm{CO}_{3}{ }^{2-}\right] /\left[\mathrm{OH}^{-}\right]$ratio. Once this new solubility equilibrium, that is, with respect to $\mathrm{Hc}$ is established, given the presence of $\mathrm{Ca}^{2+}, \mathrm{AH}_{3}$ (or its nonstoichiometric variants) and hydrogrossular phases of variable silicon content also form so as to absorb the excess aluminum species in the solution. That action is necessary to accommodate "excess aluminum" from the solution is unsurprising given that Al-equilibrium in these systems is established with respect to the AFm/AFt phases, which show very slight aqueous solubility, and very low abundances of Al-species (in the $\mu \mathrm{mol} / \mathrm{L} \mathrm{range}^{73}$ ). The lack of observation of $\mathrm{AH}_{3}$ by XRD, is explained on account of its poor crystallinity. This reasoning is supported by DTG traces shown in Fig. 15 which show higher quantities of hydrogrossular when limestone is deficient (i.e., provided by OPC only) and, $\mathrm{AH}_{3}$ when limestone present in excess. These trends are strictly linked not to the quantity of limestone present, but also the $\mathrm{CF}$, wherein a higher CF (larger OPC, and silica content) supports the formation of hydrogrossular phases, and a lower CF (lower OPC content) ensures the formation of $\mathrm{AH}_{3}$ like phases (see Fig. 15). While it is acknowledged that the uptake of aluminum into the $\mathrm{C}-\mathrm{S}-\mathrm{H}$ phases will vary with the binder chemistry (e.g., $\mathrm{Ca} / \mathrm{Si}$ ratio) and the abundance of aluminum in solution, $42,66,83$ it is not accounted for in this study due to lack of comprehensive thermodynamic data which describes the nature and extent of Al-uptake by the $\mathrm{C}-\mathrm{S}-\mathrm{H}$ as a function of its composition.

\section{Summary and Conclusions}

A series of aluminous materials were evaluated in blended binder formulations in terms of their ability to enhance the reaction of limestone in cementitious systems. Such enhancements in limestone reaction are provoked by systematic manipulation of the binder chemistry, for example, in terms of the $\mathrm{SO}_{3} / \mathrm{Al}_{2} \mathrm{O}_{3}$ and $\mathrm{CO}_{2} / \mathrm{Al}_{2} \mathrm{O}_{3}$ ratios of the binder. It is noted that in spite of the provision of sufficient aluminum, calcium and water, the extent of limestone reacted is somewhat limited. This is linked dominantly to the low reactivity (i.e., dissolution rate, and solubility) of limestone. Of all aluminous agents considered in this study, a hydratable alumina (HA) is noted to be the most successful in enhancing limestone reaction, and the formation of the $\mathrm{CO}_{3}-\mathrm{AFm}(\mathrm{Hc}$ and/or Mc) phases. On the other hand, metakaolin on account of its pozzolanic nature is most effective in ensuring strength equivalence, or improvement (in spite of reductions in the OPC content) as compared to the neat OPC formulations. Calcium aluminate cements, in spite of their substantial

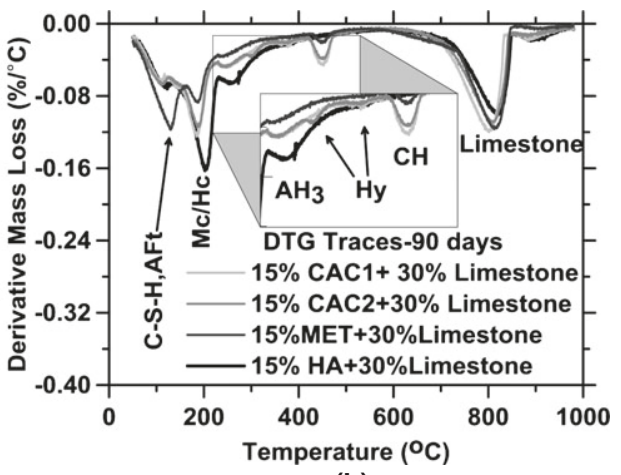

(b)

Fig. 15. DTG traces for systems containing $15 \%$ of each aluminous source after $90 \mathrm{~d}$ of hydration in: (a) limestone deficient and (b) limestone excess conditions. 
aluminum content are modestly, if at all, capable of enhancing limestone reaction. This suggests a significant role of the nature and the type of aluminum source (i.e., and not simply its aluminum content) in terms of its ability to enhance limestone reactivity in OPC-based binder systems.

The conclusions are supported by a detailed multi-method experimental study, and supporting thermodynamic calculations. In general, thermodynamic simulations are able to reliably describe hydrated phase balances except for discrepancies noted in the stability of $\mathrm{Hc}$, and $\mathrm{AH}_{3}$ in select aluminum-enriched systems, under conditions of limestone excess. This is likely on account of the slow dissolution kinetics of limestone, and/or potential kinetic restraint in the conversion of Hc to Mc. It is noted that the formation of the Hc consumes portlandite. While this is typically not problematic, if the aluminous agent were to be substantially reactive (e.g., HA) and present in a high enough dosage under conditions of limestone excess, this would result in the hydrated binder entering a "portlandite-deficient" condition. This aspect would need careful consideration given the role of portlandite in buffering the pore solution $\mathrm{pH}$-an action which prevents the decalcification of the $\mathrm{C}-\mathrm{S}-\mathrm{H}$, and ensures reinforcing steel passivation.

\section{Acknowledgments}

The authors acknowledge full financial support for this research provisioned by the University of California, Los Angeles (UCLA) and National Science Foundation (CMMI: 1066583). The authors would also like to acknowledge provision of materials by U.S. Concrete, Lehigh-Hanson, OMYA A.G., Almatis Gmbh, Kerneos Aluminates and Burgess Pigments. The contents of this study reflect the views of the authors, who are responsible for the accuracy of the datasets presented herein. This study was conducted in the Laboratory for the Chemistry of Construction Materials $\left(\mathrm{LC}^{2}\right)$ and the Molecular Instrumentation Center (MIC) at UCLA. As such, the authors acknowledge the support that has made these laboratories and their operations possible. The last author would like to acknowledge support provided by the Rice Endowed Chair in Materials Science.

\section{References}

${ }^{1}$ Concrete for the Environment. Published on Behalf of the Nordic Network Concrete for Environment by Swedish National Testing and Research Institute, Boras, Sweden, 2003

${ }^{2}$ B. Lothenbach, K. L. Scrivener, and R. D. Hooton, "Supplementary Cementitious Materials," Cem. Concr. Res., 41, 1244-56 (2011).

${ }^{3}$ R. Fernandez, F. Martirena, and K. L. Scrivener, "The Origin of the Pozzolanic Activity of Calcined Clay Minerals: A Comparison Between Kaolinite, Illite and Montmorillonite," Cem. Concr. Res., 41, 113-22 (2011).

${ }^{4}$ M. Schneider, M. Romer, M. Tschudin, and H. Bolio, "Sustainable Cement Production-Present and Future," Cem. Concr. Res., 41, 642-50 (2011).

${ }^{5}$ K. L. Scrivener, NANOCEM Internal Communication. 2003.

${ }^{6}$ V. L. Bonavetti, V. F. Rahhal, and E. F. Irassar, "Studies on the Carboaluminate Formation in Limestone Filler-Blended Cements," Cem. Concr. Res. 31, 853-9 (2001).

${ }^{7}$ T. Sato and J. J. Beaudoin, "Effect of $\mathrm{Nano}_{-} \mathrm{CaCO}_{3}$ on Hydration of Cement Containing Supplementary Cementitious Materials.," Adv. Cem. Res., 23, 1-29 (2010)

${ }^{8}$ A. Kumar, et al., "Simple Methods to Estimate the Influence of Limestone Fillers on Reaction and Property Evolution in Cementitious Materials.," Cem Concr. Composites, 42, 20-9 (2013).

${ }^{9}$ T. Oey, A. Kumar, J. W. Bullard, N. Neithalath, and G. Sant, "The Filler Effect: The Influence of Filler Content and Surface Area on Cementitious Reaction Rates.," J. Am. Ceram. Soc., 96, 1978-90 (2013).

${ }^{10} \mathrm{M}$. Nikola and C. Jolicoeur, "Influence of Superplasticizers on the Rheology and Stability of Limestone and Cement Pastes.," Cem. Concr. Res., 38 907-19 (2008).

${ }^{11}$ Annual Book of ASTM Standards. American Society for Testing and Materials, West Conshohocken, PA, 2014.

${ }^{12}$ D. L. Rayment and A. J. Majumdar, "The Composition of the C-S-H Phases in Portland Cement Pastes.," Cem. Concr. Res., 12, 753-64 (1982).

${ }^{13}$ T. Matschei, B. Lothenbach, and F. P. Glasser, "The Role of Calcium Carbonate in Cement Hydration.," Cem. Concr. Res., 37, 551-8 (2007).

${ }^{14}$ T. Matschei, B. Lothenbach, and F. P. Glasser, "The AFm Phase in Portland Cement.," Cem. Concr. Res., 37, 118-30 (2007).

${ }^{15}$ B. Lothenbach, G. Le Saout, E. Gallucci, and K. L. Scrivener, "Influence of Limestone on the Hydration of Portland Cements.," Cem. Concr. Res., 38, 848-60 (2008)

${ }^{16}$ T. Matschei, B. Lothenbach, and F. P. Glasser, "Thermodynamic Properties of Portland Cement Hydrates in the System $\mathrm{CaO}-\mathrm{Al}_{2} \mathrm{O}_{3}-\mathrm{SiO}_{2}-\mathrm{CaSO}_{4}$ $\mathrm{CaCO}_{3}-\mathrm{H}_{2} \mathrm{O}$.," Cem. Concr. Res., 37, 1379-410 (2007).

${ }^{17}$ S. Mindess, J. F. Young, and D. Darwin, Concrete. 2nd edition, Prentice Hall, Englewood Cliffs, NJ, 2003.
${ }^{18}$ F. J. Peryea and J. A. Kittrick, "Relative Solubility of Corundum, Gibbsite, Boehmite, and Diaspore at Standard State Conditions.," Clay. Clay. Miner., 36, 391-6 (1988).

${ }^{19}$ E. J. Garboczi and J. W. Bullard, "Shape Analysis of a Reference Cement.," Cem. Concr. Res., 34, 1933-7 (2004).

${ }^{20}$ J. Zhang and G. W. Scherer, "Comparison of Methods for Arresting Hydration of Cement," Cem. Concr. Res., 41, 1024-36 (2011).

${ }^{21}$ American Mineralogist Crystal Structure Database. Available at: http:// rruff.geo.arizona.edu/AMS/amcsd.php. Accessed on 01/15/2015.

${ }^{22}$ G. Le Saout, V. Kocaba, and K. L. Scrivener, "Application of the Rietveld Method to the Analysis of Anhydrous Cement," Cem. Concr. Res., 41, 133-48 (2011)

${ }^{23}$ B. H. O'Connor and M. D. Raven, "Application of the Rietveld Refinement Procedure in Assaying Powdered Mixtures," Pow. Diff., 01, 2-6 (1988).

${ }^{24}$ D. Jansen, F. Goetz-Neunhoeffer, C. Stabler, and J.Neubauer, "A Remastered External Standard Method Applied to the Quantification of Early OPC Hydration," Cem. Conc. Res., 6, 602-8 (2011).

${ }^{25}$ G. Le Saoût, B. Lothenbach, A. Hori, T. Higuchi, and F. Winnefeld, "Hydration of Portland Cement with Additions of Calcium Sulfoaluminates," Cem. Conc. Res., 8, 1-94 (2013).

${ }^{26}$ D. A. Kulik, et al., "GEM-Selektor Geochemical Modeling Package: Revised Algorithm and GEMS3K Numerical Kernel for Coupled Simulation Codes," Comput. Geosci., 17, 1-24 (2013).

${ }^{27}$ B. Lothenbach, T. Matschei, G. Möschner, and F. P. Glasser, "Thermodynamic Modelling of the Effect of Temperature on the Hydration and Porosity of Portland Cement," Cem. Concr. Res., 38, 1-18 (2008).

${ }^{28}$ M. Antoni, J. Rossen, F. Martirena, and K. Scrivener, "Cement Substitution by a Combination of Metakaolin and Limestone," Cem. Concr. Res., 12, 1579-89 (2012)

${ }^{29}$ W. Kunther, B. Lothenbach, and K. L. Scrivener, "On the Relevance of Volume Increase for the Length Changes of Mortar Bars in Sulfate Solutions," Cem. Concr. Res., 46, 23-9 (2013)

${ }^{30}$ F. Deschner, B. Lothenbach, F. Winnefeld, and J. Neubauer, "Effect of Temperature on the Hydration of Portland Cement Blended with Siliceous Fly Ash," Cem. Concr. Res., 52, 169-81 (2013).

${ }^{31}$ M. B. Haha, B. Lothenbach, G. Le Saout, and F. Winnefeld, "Influence of Slag Chemistry on the Hydration of Alkali-Activated Blast-Furnace SlagPart II: Effect of $\mathrm{Al}_{2} \mathrm{O}_{3}$," Cem. Concr. Res., 42, 74-83 (2012).

${ }^{32}$ L. Pelletier-Chaignat, F. Winnefeld, B. Lothenbach, and C. J. Müller, "Beneficial Use of Limestone Filler with Calcium Sulphoaluminate Cement," Cons. Build. Mater., 26, 619-27 (2012).

${ }^{33}$ D. A. Kulik and M. Kersten, "Aqueous Solubility Diagrams for Cementitious Waste Stabilization Systems: II, End-Member Stoichiometries of Ideal Calcium Silicate Hydrate Solid Solutions,” J. Am. Ceram. Soc., 84, 3017-26 (2001).

${ }^{34} \mathrm{~J}$. W. Bullard, et al., "Mechanisms of Cement Hydration," Cem. Concr. Res., 41, 1208-23 (2011).

${ }^{35}$ M. D. Andersen, H. J. Jakobsen, and J. Skibsted, "Incorporation of Aluminum in the Calcium Silicate Hydrate $(\mathrm{C}-\mathrm{S}-\mathrm{H})$ of Hydrated Portland Cements: A High-Field ${ }^{27} \mathrm{Al}$ and ${ }^{29} \mathrm{Si}$ MAS NMR Investigation," Inorganic. Chem., 42, 2280-7 (2003).

${ }^{36} \mathrm{~T}$. Matschei, "Thermodynamics of Cement Hydration" $\mathrm{Ph} . \mathrm{D}$. Thesis. Aberdeen University, Scotland, 2007.

${ }^{37}$ B. Lothenbach and F. Winnefeld, "Thermodynamic Modelling of the Hydration of Portland Cement," Cem. Concr. Res., 36, 209-26 (2006).

${ }^{38}$ M. Sacerdoti and E. Passaglia, "The Crystal Structure of Katoite and Implications Within the Hydrogrossular Group of Minerals," Bull. Minér., 108, 1-8 (1985).

${ }^{9}$ T. Shoji, "Ca $\mathrm{Ca}_{3} \mathrm{AI}_{2}\left(\mathrm{SiO}_{4}\right)_{3}-\mathrm{Ca}_{3} \mathrm{AI}_{2}\left(\mathrm{O}_{4} \mathrm{H}_{4}\right)_{3}$ Series Garnet: Composition and Stability," J. Miner. Soc. Jpn., 11, 359-72 (1974).

${ }^{40}$ T. G. Jappy and F. P. Glasser, "Synthesis and Stability of Silica-Substituted Hydrogarnet $\mathrm{Ca}_{3} \mathrm{Al}_{2} \mathrm{Si}_{3}-\mathrm{XO}_{12}-4 \mathrm{x}(\mathrm{OH}) 4 \mathrm{x}, "$ Adv. Cem. Res., 4, 1-8 (1991).

${ }^{41}$ Z. Yang, H. Fischer, and R. Polder, "Modified Hydrotalcites as a New Emerging Class of Smart Additive of Reinforced Concrete for Anticorrosion Applications: A Literature Review," Mater. Cor., 64, 1066-74 (2013).

${ }^{42}$ H. F. W. Taylor, and F.W. Harry. Cement Chemistry, 2nd edition. Thomas Telford, London, UK., 1997.

${ }^{43}$ L. J. Vandeperre, M. Liska, and A. Al-Tabbaa, "Microstructures of Reactive Magnesia Cement Blends," Cem. Concr. Comp., 30, 706-14 (2008).

${ }^{44}$ K. G. Ahari, J. H. Sharp, and W. E. Lee, "Hydration of Refractory Oxides in Castable Bond Systems-I: Alumina, Magnesia, and Alumina-Magnesia Mixtures," J. Eur. Ceram. Soc., 22, 495-503 (2002).

${ }^{45}$ K. G. Ahari, J. H. Sharp, and W. E. Lee, "Hydration of Refractory Oxides in Castable Bond Systems-II: Alumina-Silica and Magnesia-Silica Mixtures," J. Eur. Ceram. Soc., 23, 3071-7 (2003).

${ }^{46}$ R. Snellings, A. Salze, and K. L. Scrivener, "Use of X-ray Diffraction to Quantify Amorphous Supplementary Cementitious Materials in Anhydrous and Hydrated Blended Cements," Cem. Conc. Res., 64, 89-98 (2014).

${ }^{47}$ K. L. Scrivener, et al., "TC 238-SCM: Hydration and Microstructure of Concrete with SCMs," Mater. Struct., 48, 835-62 (2015).

${ }^{48}$ P. Gu, J. J. Beaudoin, E. G. Quinn, and R. E. Myers, "Early Strength Development and Hydration of Ordinary Portland Cement/Calcium Aluminate Cement Pastes," Adv. Cem. Based Mater., 6, 53-8 (1997).

${ }^{49} \mathrm{P}$. Gu and J. J. Beaudoin, "A Conduction Calorimetric Study of Early Hydration of Ordinary Portland Cement/High Alumina Cement Pastes," $J$. Mater. Sci., 32, 3875-81 (1997).

${ }^{50}$ H. J. Kuzel, "Initial Hydration Reactions and Mechanisms of Delayed Ettringite Formation in Portland Cements," Cem. Concr. Comp., 18, 195-203 (1996). 
${ }^{51}$ A. Violante and P. M. Huang, "Formation Mechanism of Aluminum Hydroxide Polymorphs," Clay.Clay. Miner., 41, 590-7 (1993).

${ }^{52}$ D. Damidot, S. Stronach, A. Kindness, M. Atkins, and F. P. Glasser, "Thermodynamic Investigation of the $\mathrm{CaO}-\mathrm{Al}_{2} \mathrm{O}_{3}-\mathrm{CaCO}_{3}-\mathrm{H}_{2} \mathrm{O}$ Closed System at $25^{\circ} \mathrm{C}$ and the Influence of $\mathrm{Na}_{2} \mathrm{O}$," Cem. Concr. Res., 24, 563-72 (1994).

${ }^{53}$ D. Damidot, B. Lothenbach, D. Herfort, and F. P. Glasser, "Thermodynamics and Cement Science," Cem. Concr. Res., 41, 679-95 (2011).

${ }^{54}$ D. P. Bentz, "Modeling the Influence of Limestone Filler on Cement Hydration Using CEMHYD3D," Cem. Concr. Comp., 28, 124-9 (2006).

${ }_{55}$ A. S. Silva, A. Gameiro, J. Grilo, R. Veiga, and A. Velosa, "Long-Term Behavior of Lime-Metakaolin Pastes at Ambient Temperature and Humid Curing Condition," App. Cl. Sci., 88, 49-55 (2014).

${ }^{56}$ P. S. De Silva and F. P. Glasser, "Phase Relations in the System $\mathrm{CaO}$ $\mathrm{Al}_{2} \mathrm{O}_{3} \quad \mathrm{SiO}_{2} \quad \mathrm{H}_{2} \mathrm{O}$ Relevant to Metakaolin-Calcium Hydroxide Hydration," Cem. Conc. Res., 23, 627-39 (1993).

${ }^{57}$ K. Kwan, J. LaRosa-Thompson, and M. W. Grutzeck, "Structures and Phase Relations of Aluminum-Substituted Calcium Silicate Hydrate," J. Am. Ceram. Soc., 79 [4] 967-71 (1996).

${ }^{58}$ A. Kumar, J. Reed, and G. Sant, "Vertical Scanning Interferometry: A New Method to Measure the Dissolution Dynamics of Cementitious Minerals," J. Am. Ceram. Soc., 96, 2766-78 (2013).

${ }^{59}$ G. Falzone, M. Balonis, and G. Sant, "X-AFm Stabilization as a Mechanism of Bypassing Conversion Phenomena in Calcium Aluminate Cements" Cem. Concr. Res., 72, 54-68 2015.

${ }^{60}$ A. P. Luz and V. C. Pandolfelli, " $\mathrm{CaCO}_{3}$ Addition Effect on the Hydration and Mechanical Strength Evolution of Calcium Aluminate Cement for Endodontic Applications," Ceram. Inter., 38, 1417-25 (2012).

${ }^{61}$ G. Puerta-Falla, G. Falzone, and G. Sant. Unpublished Results, University of California Los Angeles, Los Angeles, CA, 2014.

${ }^{62}$ J. M. Makar and T. Sato, "The Effect of Drying Method on Ordinary Portland Cement Surfaces During the Early Stages of Hydration," Mater. Struct., 46, 1-12 (2013).

${ }^{63}$ K. Vance, A. Kumar, G. Sant, and N. Neithalath, "The Rheological Properties of Ternary Binders Containing Portland Cement, Limestone, and Metakaolin or Fly Ash," Cem. Concr. Res., 52, 196-207 (2013).

${ }^{64}$ K. Vance, M. Aguayo, T. Oey, G. Sant, and N. Neithalath, "Hydration and Strength Development in Ternary Portland Cement Blends Containing Limestone and Fly Ash or Metakaolin," Cem. Concr. Comp., 39, 93-103 (2013).

${ }^{65}$ M. Zajac and M. Ben Haha, "Experimental Investigation and Modeling of Hydration and Performance Evolution of Fly Ash Cement," Mater. Struct., 47, 1259-69 (2014).

${ }^{66} \mathrm{P}$. Faucon, T. Charpentier, A. Nonat, and J. C. Petit, "Triple-Quantum Two-Dimensional ${ }^{27} \mathrm{Al}$ Magic Angle Nuclear Magnetic Resonance Study of the Aluminum Incorporation in Calcium Silicate Hydrates," J. Am. Chem. Soc., 120 [46] 12075-82 (1998)

${ }^{67}$ D. Damidot and F. P. Glasser, "Investigation of the $\mathrm{CaO}-\mathrm{Al}_{2} \mathrm{O}_{3}-\mathrm{SiO}_{2}$ $\mathrm{H}_{2} \mathrm{O}$ System at $25^{\circ} \mathrm{C}$ by Thermodynamic Calculations," Cem. Concr. Res., 25 22-8 (1995)

${ }^{68}$ M. Balonis and F. P. Glasser, "The Density of Cement Phases," Cem. Concr. Res., 39, 733-9 (2009).
${ }^{69}$ M. Balonis, "The Influence of Inorganic Chemical Accelerators and Corrosion Inhibitors on the Mineralogy of Hydrated Portland Cement Systems", Ph.D. Thesis. University of Aberdeen, Scotland, 2010.

${ }^{70}$ M. Whittaker, M. Zajac, M. Ben Haha, F. Bullerjahn, and L. Black, "The Role of the Alumina Content of Slag, Plus the Presence of Additional Sulfate on the Hydration and Microstructure of Portland Cement-Slag Blends," Cem. Concr. Res., 66, 91-101 (2014).

${ }^{71}$ L. Baquerizo, T. Matschei, and K. Scrivener, "The Impact of Water Chemical Potential on the Hydration States of Monosulfoaluminate"; Presented at the 31 st cement and concrete Science Conference. London, 2011.

${ }^{72}$ G. Renaudin, A. Mesbah, C. Cau-dit-Coumes, F. Frizon, and F. Leroux, "Chloride and Carbonate Immobilisation by Monosulfoaluminate: Study of the Solid Solutions in the $\mathrm{CO}_{3}{ }^{2-}-\mathrm{Cl}^{-}-\mathrm{SO}_{4}{ }^{2-}$ AFm Systems"; XIII International Congress on the Chemistry of Cement (ICCC), Conference Proceedings. Madrid, 2011

${ }^{73}$ G. Sant. Unpublished Results. University of California Los AnglesUCLA, Los Angeles, CA, 2014.

${ }^{74}$ M. Nouri-Khezrabad, M. A. L. Braulio, V. C. Pandolfelli, F. GolestaniFard, and H. R. Rezaie, "Nano-Bonded Refractory Castables," Ceram. Inter. 39, 3479-97 (2013).

${ }^{75}$ J. Moon, J. E. Oh, M. Balonis, F. P. Glasser, S. M. Clark, and P. J. M. Monteiro, "High Pressure Study of Low Compressibility Tetracalcium Aluminum Carbonate Hydrates $3 \mathrm{CaO} \cdot \mathrm{Al}_{2} \mathrm{O}_{3} \cdot \mathrm{CaCO}_{3} \cdot 11 \mathrm{H}_{2} \mathrm{O}$," Cem. Concr. Res., 42, 105-10 (2012)

${ }^{76}$ S. Tsivilis, E. Chaniotakis, E. Badogiannis, G. Pahoulas, and A. Ilias, "A Study on the Parameters Affecting the Properties of Portland Limestone Cements," Cem. Concr. Comp., 21, 107-16 (1999).

${ }^{77}$ G. Menéndez, V. Bonavetti, and E. F. Irassar, "Strength Development of Ternary Blended Cement with Limestone Filler and Blast-Furnace Slag," Cem. Concr. Comp., 25, 61-7 (2003).

${ }^{78}$ S. Das, et al., "The Fracture Response of Blended Formulations Containing Limestone Powder: Evaluations Using Two Parameter Fracture Model and Digital Image Correlation," Cem. Concr. Comp., 53, 316-26 (2014).

${ }^{79}$ K. De Weerdt, M. Ben Haha, G. Le Saout, K. O. Kjellsen, H. Justnes, and B. Lothenbach, "Hydration Mechanisms of Ternary Portland Cements Containing Limestone Powder and Fly Ash," Cem. Concr. Res., 41 [3] 279-91 (2011).

${ }^{80}$ G. Le Saoût, B. Lothenbach, A. Hori, T. Higuchi, and F. Winnefeld, "Hydration of Portland Cement with Additions of Calcium Sulfoaluminates," Cem. Concr. Res., 43, 81-94 (2013).

${ }^{81}$ J. Moon, et al., "High Pressure Study of Low Compressibility Tetracalcium Aluminum Carbonate Hydrates $3 \mathrm{CaO} \cdot \mathrm{Al}_{2} \mathrm{O}_{3} \cdot \mathrm{CaCO}_{3} \cdot 11 \mathrm{H}_{2} \mathrm{O}$," Cem Conc. Res., 42 [1] 105-10 (2012).

${ }^{82}$ J. Moon, J. E. Oh, M. Balonis, F. P. Glasser, S. Clark, and P. J. M. Monteiro, "Pressure Induced Reactions Amongst Calcium Aluminate Hydrate Phases," Cem. Conc. Res., 41 [6] 571-8 (2012).

${ }^{83}$ R. J. Myers, E. L'Hôpital, J. L. Provis, and B. Lothenbach, "Effect of Temperature and Aluminum on Calcium (Alumino) Silicate Hydrate Chemistry Under Equilibrium Conditions," Cem. Concr. Res., 68, 83-93 (2015). 